\title{
Caracterização, hábitos alimentares e reprodutivos de quatro espécies de "aracus" e consideraçōes ecológicas sobre o grupo no lago Janauacá-AM. (Osteichthyes, Characoidei, Anostomidae)
}

\author{
Geralds Mendes dos Santos ( ${ }^{(*)}$
}

\begin{abstract}
Resumo
Em continuidade ao estudo dos anostomideos amazônicos, são apresentadas informações sobre caracterização, hábitos alimentares e reprodutivos de quatro espécies do grupo no lago Janauacá-AM (Laemolyta varia, Leporinus friderici, Leporinus fasciatus e Leporinus trifasciatus). Foram analisados individuos de vários tamanhos, coletados quinzenalmente durante um ano e meio. Apesar de serem morfologicamente bem distintas e facilmente identificadas, as espécies passam por profundas modificações quanto ao padrão de colorido, sendo as formas jovens muito distintas das adultas. São todas onivoras, alimentando-se basicamente do ninfas de insetos aquáticos e de sementes. Reproduzemse na boca do lago ou mesmo em suas margens, na enchente (janeiro a abril) quando as águas do rio Solimões invadem os lagos de várzea. Há nesta época uma grande proliferaçāo dos capins aquáticos flutuantes, sob os quais geralmente vivem os alevinos. São apresentadas ainda algumas consideraçōes sobre a morfologia do trato digestivo em relação ao regime aimentar e esboçadas algumas correlaçōes entre estas espécies e outras do grupo anteriormente estudadas.
\end{abstract}

\section{INTRODUÇÃo}

Representantes da familia Anostomidae são relativamente bem conhecidos quanto ao asperto sistemático, principalmente através dos trabalhos de Garman, (1890); Eigenmann, (1912); Borodin, (1929); Campos, (1945); Fowler, (1948/51); Myers (1950); Gery (1960, 1961, 1972/73, 1977); Rinquelet et al. (1967): Winterbottom (1980). Entretanto nestes autores, como na maioria dos trabalhos de sistemática de peixes amazônicos, os resultados são baseados apenas em exemplares adultos e preservados, dificultando uma real e segura identificação das formas jovens e do materíal no campo. Este fato é crítico para o adequado conhecimento dos anostomídeos que geralmente apresentam grandes variações de alometria e de padrão de colorido, durante seu desenvolvimento ontogenético (Gery, 1964, 1972/73; Britski \& Garavello, 1978; Santos, 1980).

Quanto à bioecologia do grupo, muito pouco se conhece, sendo a maioria das informações apenas parciais porque baseadas em pequeno número de exemplares ou $\mathrm{em}$ poucas coietas. Entre os trabalhos de ecologia que mencionam algumas espécies de anostomídeos amazônicos, destacam-se os de Lowe-McConnell (1964); Marlier (1968); Knoppel, 1970. 1972); Saul (1975); Soares, (1978); Goulding (1981) Santos (1981).

Estudos sobre este grupo de peixes são de granıle importância, principalmente por tratarse de espécies com uma ampla distribuição geográfica na América do Sul (Gery, 1961) e por conter representantes de alto valor para a pesca e por conseguinte para a alimentação humana (Petrere Jr., 1978; Dourado. 1981) além de algumas espécies já serem emprega. das na piscicultura brasileira (Fontenelle \& Vasconcelos, 1977) e de outras terem alto valor na aq̣uariofilia (Axelrod et al, 1962; SUDEPE, 1979).

Este trabalho é a complemientação de uma série que se refere à caracterização e bioecologia de "aracus" na Bacia Amazônica, abordando especificamente o resultado do inventário do grupo, no lago Janauacá e considerando a descrição da morfologia de algumas estruturas do tiato digestivo, a variação ontogenética do padrāo de colorido e a análise dos hábitos ali. mentares e reprodutivos de indivíduos de diferentes classes de idade e durante um ciclo anuaı completo, das seguintes espécies: Laemolyla varía Garman, 1890; Leporínus triderici (Bloch) 1794; Leporinus fasciatus (Bloch. 1794) e Leporinus trifasciatus Steindachner, 1876.

(") - Instituto Nacional de Pesquisas da Amazônia, Manaus. 


\section{MATERIAL E MÉTODOS}

Os peixes do presente estudo foram coletados quinzenalmente, entre abril de 1977 a agosto de 1978, no Janauacá, um lago de vár. zea do rio Solimões, a cerca de $60 \mathrm{~km}$ a sudoeste de Manaus, com uso de redinhas e de malhadeiras de vários tipos de malha e simultaneamente, tendo sempre em vista a captura de inidividuos de todos os tamanhos e em diferentes biótopos (água abertá, margem, igapó e sob as macrófitas flutuantes) .

O material coletado era fixado em formol a $4 \%$, lavado em água corrente após cerca de dois meses e fixado em álcool a $70 \%$. A maioria das observações dos estágios gonadais foi feita no local de coleta, sendo o restante do trabalho executado em laboratório na sede do INPA, em Manaus.

A contagem dos rastros branquiais foi efetuada no primeiro arco branquial esquerdo, considerando separadamente os da fileira interna e da externa; na quantificação dos dentes faringeanos, considerou-se também os dentes das duas placas superiores e da inferior separadamente. O estômago e o intestino foram distendidos e medidos sobre régua milimetrada.

0 estudo da dieta alimentar foi realizado apenas pela análise do conteúdo estomaca!, utilizando-se de lupa e microscópio e avaliada através de métodos qualitativo (freqüência de ocoriência) e quantitativo (freqüência relativa cios pontos) de acordo com a descrição de Hynes (1950); Corbet (1961), com algumas modificeções (Santos, 1981), exceto que, ao invés de pontos estipulados, considerou-se as fieqüências relativas encontradas para cada ítem. O cálculo do grau médio de repleção (Gr) foi efetuado segundo a expressão:

$$
\mathrm{Gr}=\frac{\sum \mathrm{i} . \mathrm{fa}}{\sum \mathrm{fa}} \text {, sendo " } \mathrm{i} \text { " o número de pontos }
$$

obtidos para cada grau de enchimento dos estômagos e " $f$ " a freqüência ábsoluta de estômagos com grau " $i$ " de enchimento. Os pontos estipulados foram: $O$ (vazio); 0,5 (até cercs de $10 \%$ cheio); 1 (cerca de $1 / 4$ cheio): 2 (cerca de $2 / 4$ cheio); 3 (cerca de $3 / 4$ cheio) e 4 (cerca de $4 / 4$ cheio) .
A natureza dos ítens alimentares encontrados e na ordem de listagem nas figuras é a seguinte :

Detritos - material orgânico quase totalmente digerido e de muito difícil identificação, possivelmente compreendendo os mesmos alimentos encontrados normalmente e identificados abaixo;

Efemerópteros - maioria constituída de ninfas e em parte por ovos e sub imago de Ãstenopus sp.;

Dipteros - em sua grande maioria corresponde a ninfas de espécies de Ceratopogonidae e de Chironomidae;

Microcrustáceos - compreendem espécies de Ostiacoda e Cladocera;

Outros artrópodos - engloba restos quitinosos ou partes de insetos adultos (predo. minando Hymenoptera e Coleoptera) $€$ aranhas;

Briozoários - constituídos por estatoblastos ou formas assexuadas e de resistência desses animais;

Escamas - compreendem escamas cicloides, pequenas, presumivelmente de espécies cie caracoideos;

Peixes - compreendem pedaços de peixes ou pequenos caracoideos;

Moluscos - constituídos de conchas de Pelecipoda; predominaram espécies do gênero Eupera;

Rotíferos - representados na maioria por espécies de Keratella;

Esponjas - compreendem espículas cilíndricas, claras, de extremidades pontiagudas de espécies de Spongilidae;

"Coarse-litter" - constituído por pedaços de madeira ou galhos secos apodrecidos;

Material vegetal - formado por pedaços de vegetais, geralmente folhas secas e pequenos ramos;

Frutc-Semente - formado por frutos e sementes, geralmente de Cecropia, Graminae e outros. Ocorrem geralmente quebrados;

Algas - compreendem geraimente algas filamentosas (maioria Chlorophyta) e unicelulares (maioria Diatomáceas). 
Para tentar avaliar o grau de sobreposição alimentar nas diferentes estações estabelecidas (veja adiante) e entre as quatro espé. cies aqui estudadas bem como entre as demais tratadas anteriormente (Santos, 1981), utilizou. se o mesmo cceficiente de sobreposição alimentar descrito por Morisita, (1959), comenta. do em Zaret \& Rand (1971), segundo a expressão .

$$
c \lambda=\frac{2 \sum_{i=1}^{s} X i \cdot Y i}{\sum_{i=1}^{s} X i^{2}+y^{2}}
$$

sencio " $\mathrm{s}$ " o número total de categorias de alimentos; " $X$ " a proporção da ćieta da espécie $X$ em relação à categoria alimentar " $i$ " $e$ " $Y$ ". o mesmo para a espécie $Y$.

Para o estudo da reprodução procurou-se, após várias observações no campo e no laboratório, caracterizar os diferentes estágios gonadais, avaliar suas freqüências relativas, tomando-se por base a escala proposta per Nikoiski, (1963) e adaptada por Santos (1981) para três espécies de Anostomidae. O cálculc do grau médio de maturação $(\mathrm{Gm})$, a exemplc do cálculo do $\mathrm{Gm}$, foi efetuado segundo a expressão :

$$
\mathrm{Gm}=\frac{\sum \mathrm{i} \cdot \mathrm{fa}}{\sum \mathrm{fa}}
$$

sendo " $\mathrm{i}$ " o número de pontos atribuídos para cada estágio e "fa", a freqüêtıcia absoluta dos estágios consicierados com " $\mathrm{i}$ " pontos. Para a quantificação dos pontos " $\mathrm{i}$ " de cada estágio atribuiu-se algarismos arábicos aos romanos correspondentes; por exemplo: estágio II, 2 pontos; estágio III, 3 pontos e assim sucessivamente.

As estações consideradas foram tomadas de acordo com o nível do rio Negro (dados da Administração do Porto de Manaus), no período considerado, sendo "alta" a correspondente aosmmeses de maio a julho; "abaixando", de agosto e setembro: "baixa" de outubro, a dezembro e "elevando" de janeiro a abril.

\section{Resultados}

ABUNDÂNCIA RELATIVA DAS ESPÉCIES

Após mais de um ano de investigaçōes nc lago e também considerando os resultados de outras coletas realizadas no mesmo periodo por outros pesquisadores do INPA, foi possive! Inventariar 15 espécies de Anostomidae, duas das quais provavelmente novas. Considerandose apenas os dados de coletá efetuada pelo autor e com usc de malhadeiras (praticamente todos os adultos das espécies aqui tratadas ioram capturados com este aparelho) e em relação ao período total de coleta, Schizodon fasciatus roi a espécie dominante $(54,3 \%$ dos individuos coletados), seguindo-se Rhytiodus microlejis e Laemolyta varia $(19,5$ e $15,2 \%$ respectivamente). As demais espécies coletadas são pouco freqüentes (cerca de $10 \%$ dos indivíduos coletados).

Considerando-se a freqüência relativa das espécies por estação, $S$. fasciatus foi dominante na "baixa" $(80,5 \%)$ e "abaixando", $(69,8 \%)$; L. varia, dominante na "elevando" $(40,3 \%)$ e R. microlepis, dominante na "alta" $(46,2 \%)$. (Tabela no 1 fig. 1).

Apesar de a maioria dos peixes adultos ser coletada com malhadeira, 5 espécies foram capturadas só com redinha, em número muito reduzido de exemplares e em raras ocasiōes (tabela $n^{\circ}$ 1).

\section{CARACIERIZAÇÃO DAS ESPECCIES}

Os caracteres sistemáticos mais utilizados para a descrição e identificação das espécies de Anostomidae são a posição da boca, forma, número e arranjo dos dentes bucais, número de escamas da linha lateral, acima e abaixo dela, e o padrão de colorido. Os dados apresentados na tabela $\mathrm{n}^{\circ} 2$ associados a outros citados na caracterização a seguir são suficientes para separá-las e identificá-las segu. ramente.

\section{a - Dentes bucais (fig. 2).}

As quatro espécies, como todas as demais da familia, apresentam boca com pequena amplitude e no máximo 8 dentes em cada maxilar. Laemolyta varia apresenta boca superior. 
TABELA 1 - Freqüências absoluta e relativa das espécies de Anostomidae coletadas só com malhadeiras e só com redinha no lago Janauacá nas diferentes "estações" do ano.

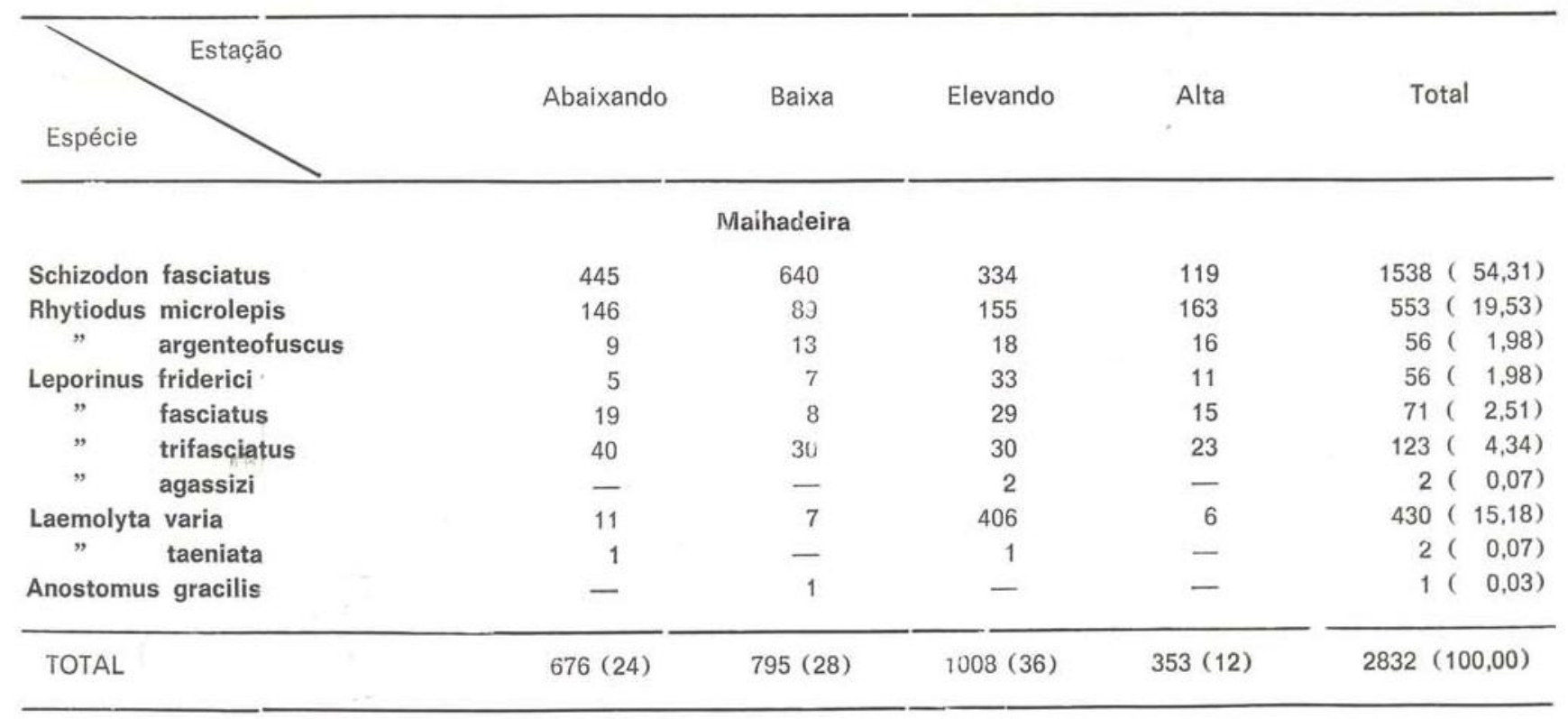

Redinha

\begin{tabular}{|c|c|c|c|c|c|}
\hline Abramites hypselonotus & - & 10 & - & - & $10(22,73)$ \\
\hline Leporinus sp 1 & 28 & 2 & - & - & $30(68,18)$ \\
\hline$" \quad$ sp 2 & - & - & 2 & - & $2(4,55)$ \\
\hline Laemolyta garmani & - & - & - & 1 & $1(2,27)$ \\
\hline Amostomus gracilis & - & 1 & - & - & $1(2,27)$ \\
\hline TOTAL & $28(64)$ & $13(29)$ & $2(5)$ & $1(2)$ & $44(100,00)$ \\
\hline
\end{tabular}

sendo terminal a subinferior nas três espécies de Leporinus. Em L. fasciatus e Laemolyta variá os lábios são fortemente carnosos e franjados; nas demais, lisos. Na base interna dos dentes sinfisianos do premaxilar de $L$. trifas ciatus, ocorre uma protuberância calosa, no ponto de contato com os dentes medianos da mandíbula quando a boca se encontra fechada. Em todas as espécies os dentes da mandíbula. apoiam-se internamente, em relação aos dentes do maxilar superior, quarido a boca está fechada.

Cis dentes são em número de 8 no premaxilar e 8 no dentario em todas as espécies, exceto em $L$. trifasciatus em que são em númerr. de 6 em cada maxilar. Em todas elas, os dentes diminuem de tamanho a partir da sínfi. se. Nas espécies de Leporinus os dentes do premaxilar são menores e mais truncados que os do dentărio e com disposição escalariforme, ao contrário dos da mandíbula que são cônizos e maiores e em disposição linear. En
L. varia, os dentes do premaxilar são pluricuspidados e os clo dentário planos, ambos com disposição linear.

\section{b - Rastros branquia's (fig. 3 e 4).}

São curtos (cerca de 3 a $4 \mathrm{~mm}$ ), carnosos e dispostos em duas fileiras, uma de cada lado do arco branquial. A variação do número de rastros foi menor na face "literna do que na externa, sendo que a amplitude total nas duas faces foi de 18 a $24 \mathrm{em} \mathrm{L.} \mathrm{varia;} 21$ a $29 \mathrm{em}$ L. friderici; 21 a $26 \mathrm{em} \mathrm{L.} \mathrm{fasciatus} \mathrm{e} 22$ a 30 em $L$. trifasciatus, com média menor em L. varia (cerca de 21) e maior $\mathrm{em} \mathrm{L.} \mathrm{trifasciatus}$ (cerca de 26).

\section{$\mathrm{s}-$ Dentes faringeanos (fig. 5 e 6 ).}

São curtos (cerca de $2 \mathrm{~mm}$ ), cônicos, uni a bicuspidados e alojados em três "almofadas" carnusas, sendo uma inferior, triangular e duas superiores, arredondadas, localizadas nos últimos 4 e 5 arcos branquiais, respectivamente, 
a um mesmo nível. As cúspides dos dentes superiores são voltados para trás e as dos dentes inferiores, para a frente.

Considerados na contagem conjuntamente, a média de dentes das duas placas superiores

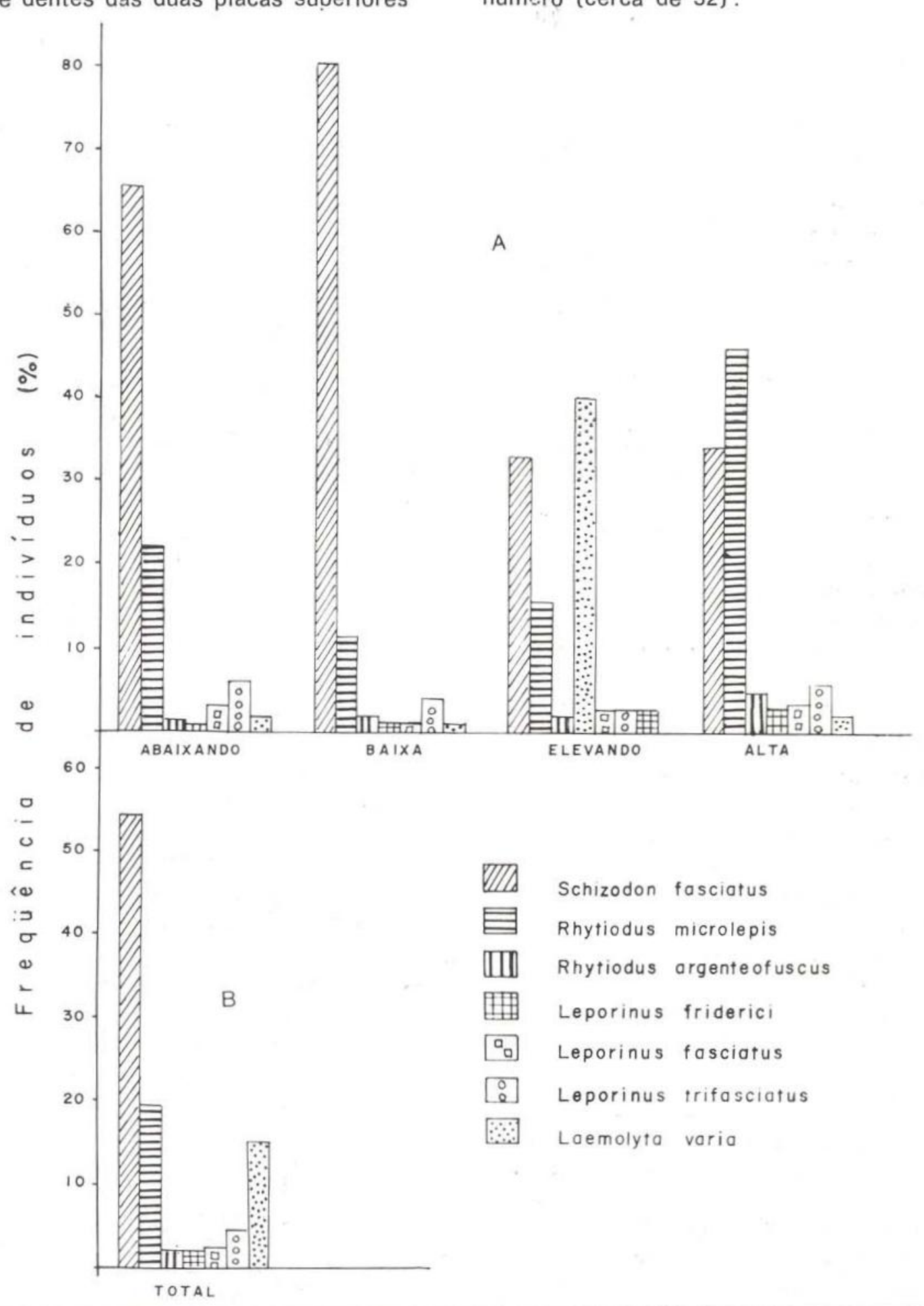

apresentou-se em menor número (cerca de 33) do que os da placa inferior (cerca de 42) em todas as espécies, exceto em $L$. varia em que se apresentou mais ou menos com o mesmo número (cerca de 32 ) . 

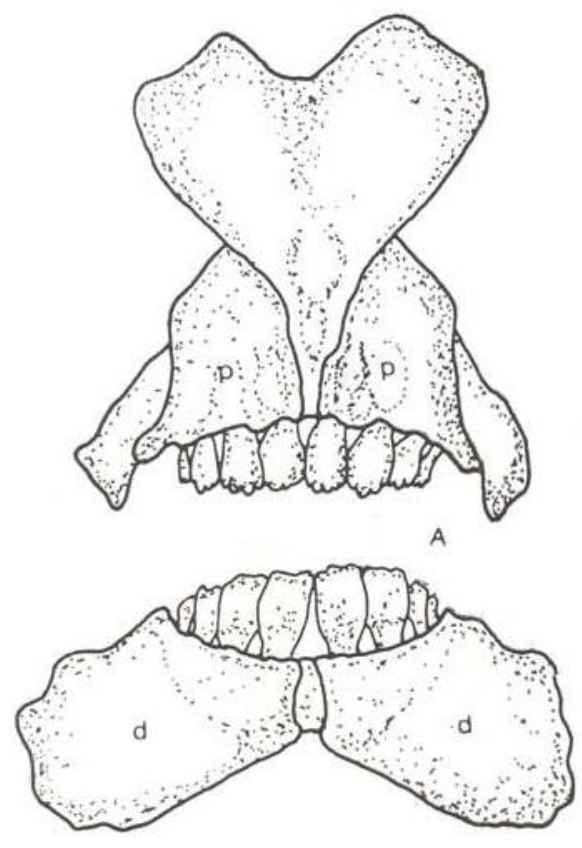

贯
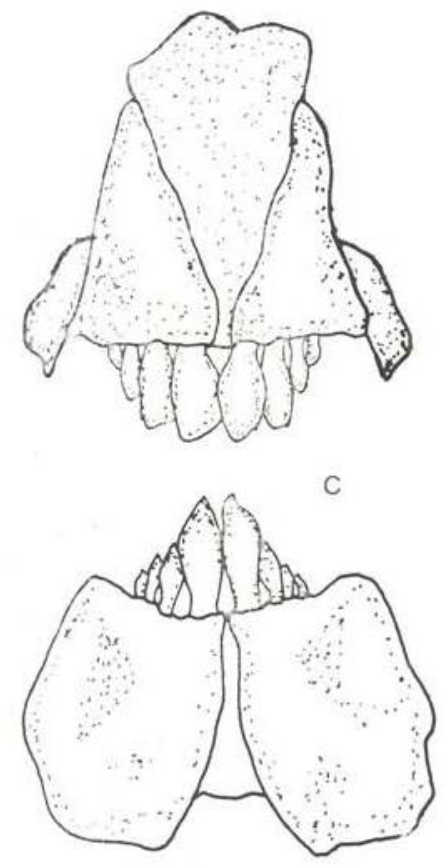
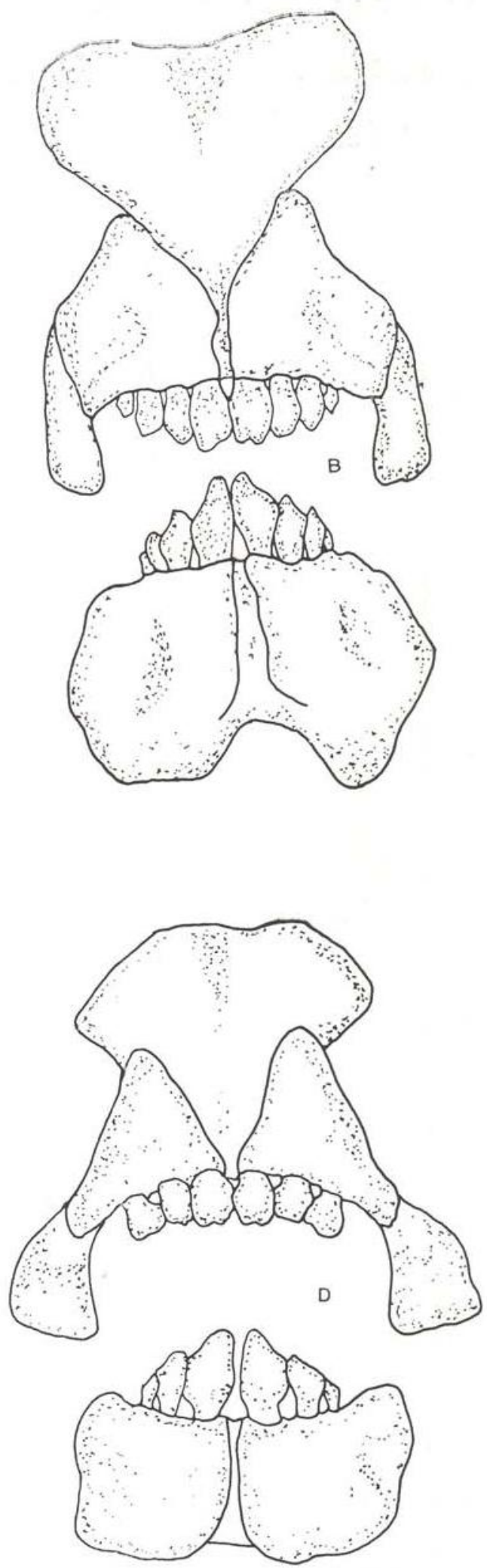

Fig. 2 - Estrutura e disposição dos dentes bucais no premaxilar (p) e no dentário (d) em Laemolyta varia (A), Le. porinus friderici (B), L. fascatus (C), e L. trifasciatus (D). 


\section{d-Cecos pilóricos (fig. 7 e 8).}

São cilíndricos e alongados (cerca de $20 \mathrm{~mm}$ ) e indivídualizados, localizando-se na regiào anterior do intestino, próximo ao piloro. $\mathrm{O}$ número total variou muito pouco nas quatro espécies, com médias entre 11 e 13 e amplitude total de 9 a 15 .

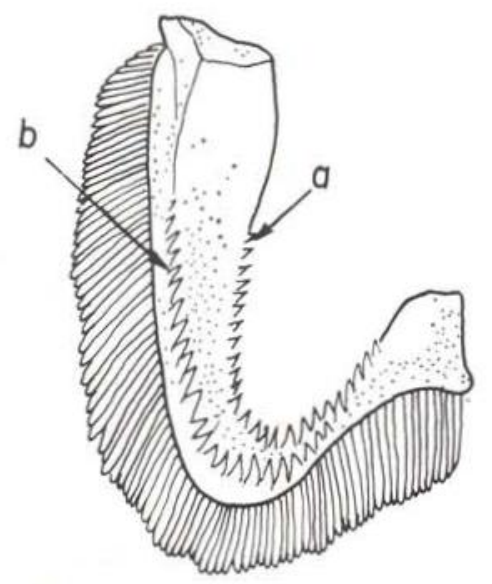

Fig. 3 - Disposição dos rastros branquiais nas faces interna (a), externa (b) do primeiro arco branquial das quatro espécies estudadas.

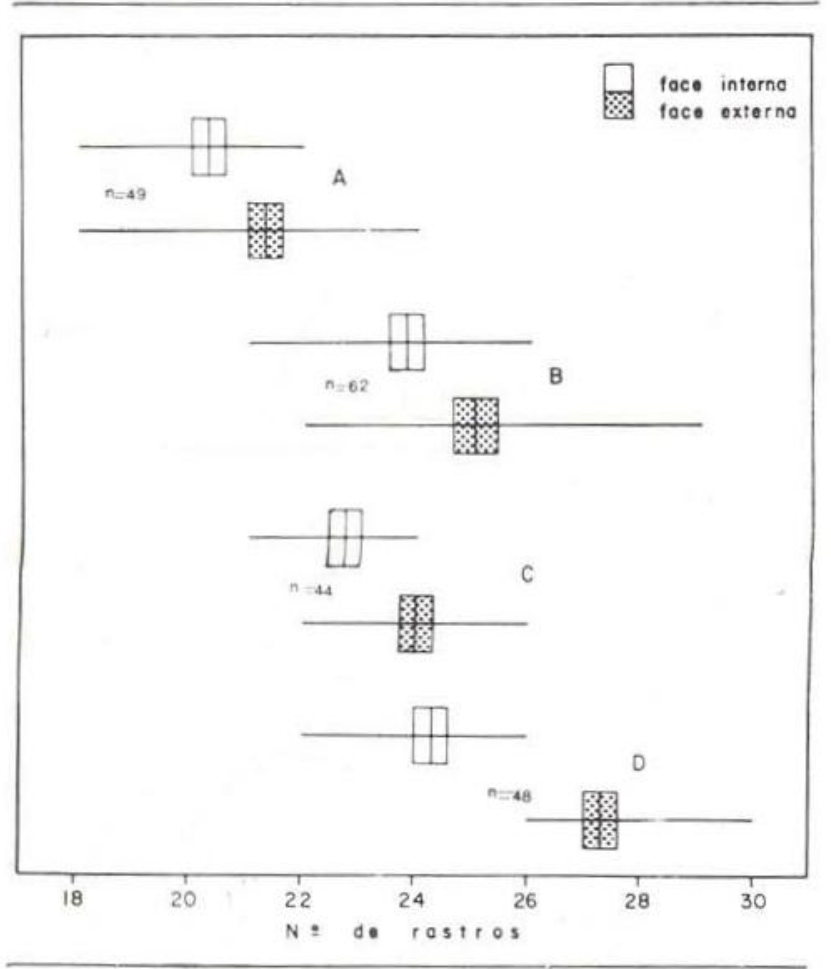

Fig. 4-Amplitude da variação do número de rastros branquiais em Laemolyta varia (A), Leporinus friderici (B), $\mathrm{L}$. fasciatus (C) e L. trifasciatus (D). O traço vertical representa a média aritmética; o horizontal, a variação total e o retângulo, o intervalo de confiança.

Caracterização...

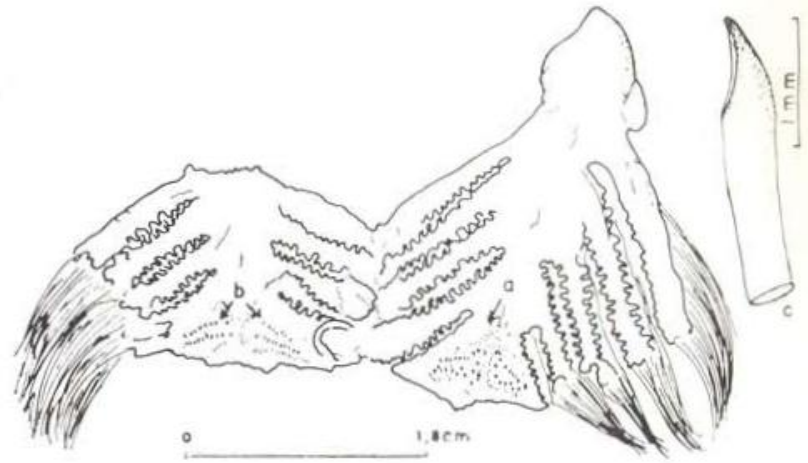

Fig. 5 - Esquema da disposição das placas faringeanas inferior (a), superior (b) e estrutura dos dentes faringeanos (c) das espécies estudadas.

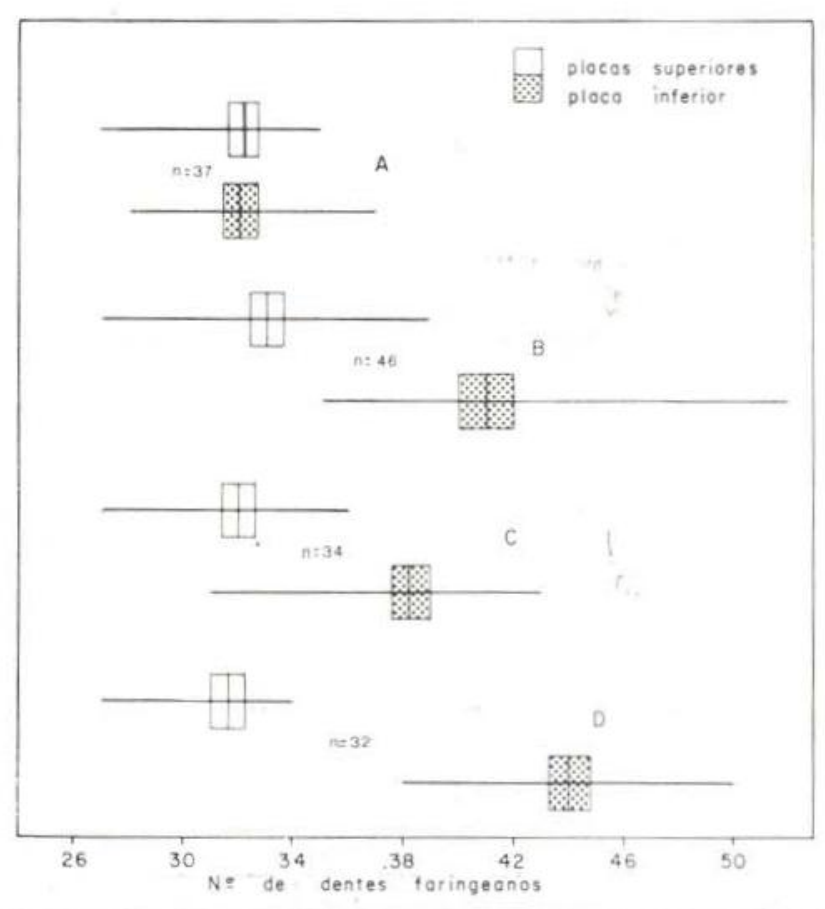

Fig. 6 - Amplitude da variação do número de dentes faringeanos em Laemolyta varia (A), Leporinus friderici (B), L. fasciatus (C) e L. trifasciatus (D). Representação como a da fig. 4 .

\section{e - Estômago (fig. 7 e 9).}

Apresenta-se em forma de saco, com duas porções aproximadamente de mesmo tamanho, uma descendente e outra ascendente. As paredes são finas (menos de $1 \mathrm{~mm}$ de espessura) e a parte interna, anterior, franjada. O coefi. ciente estomacal, isto é, a relação entre o comprimento do estômago e o comprimento padrãc do peixe, apresentou uma média muito próximo entre jovens e adultos das quatro espécies, 


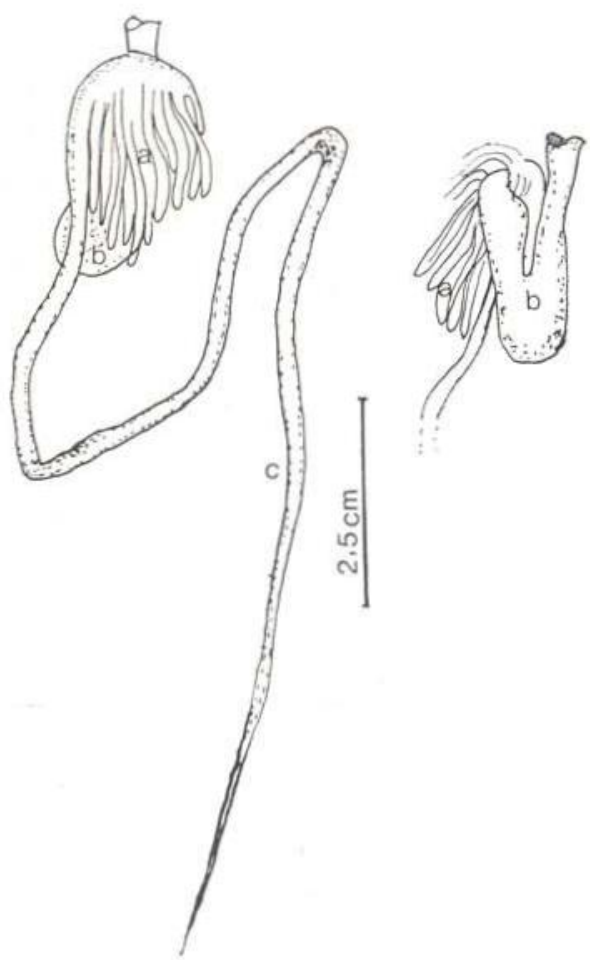

Fig. 7 - Estrutura e disposição dos cecos pilóricos (a), estômago (b) e intestino (c) nas quatro espécies estudadas.

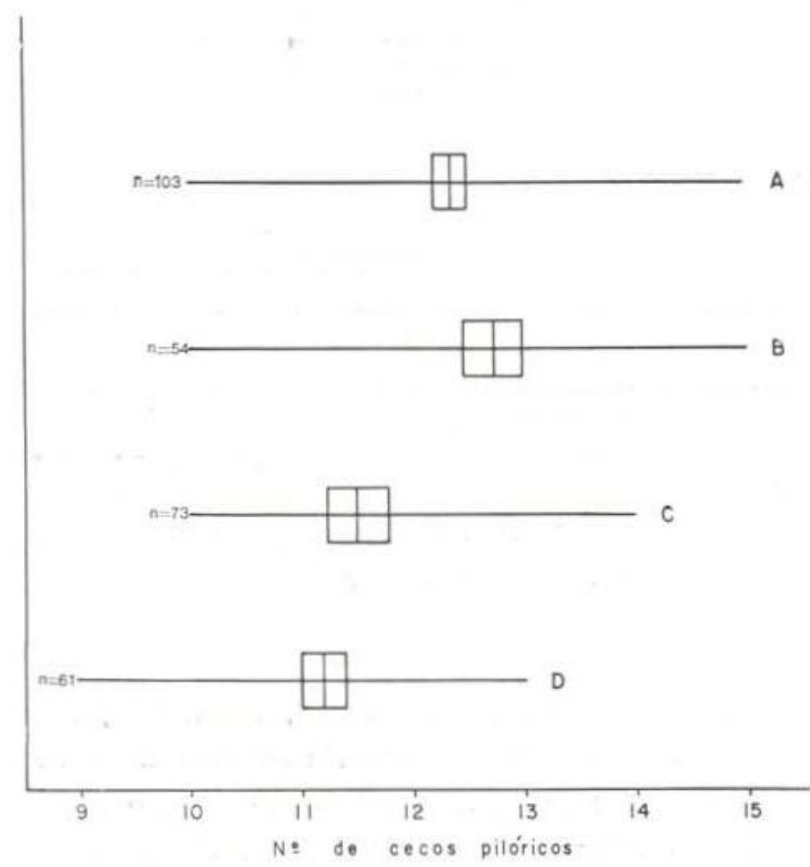

Fig. 8 - Amplitude da variação do número de cecos pilóricos em L. waria (A), L. friderici (B), L. fasciatus (C) e L. trifasciatus (D). Representação como a da fig. 4.
$(0,23$ a 0,35$)$ e sendo pouco maior em Leporinus trifasciatus $(0,30$ a 0,35$)$ que nas demais espécies $(0,25$ a 0,30$)$.

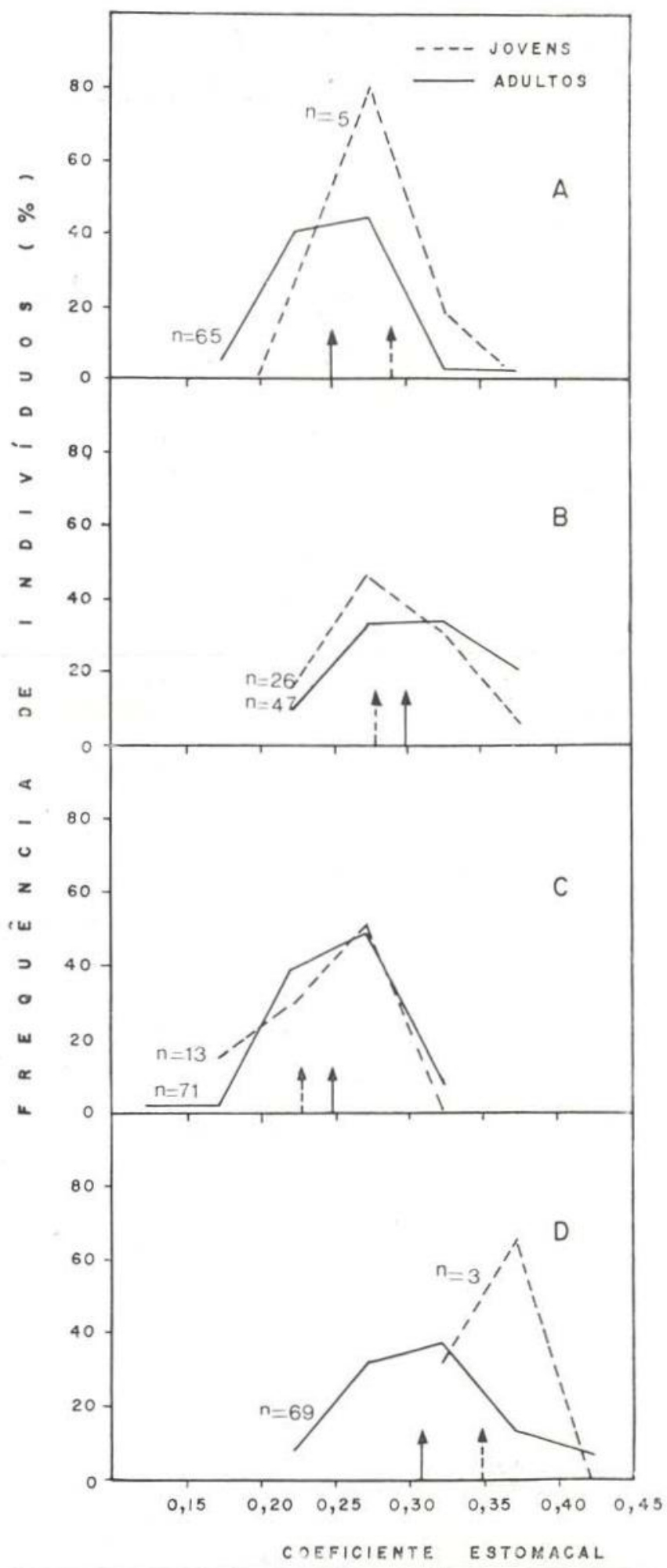

Fig. 9 - Distribuição e média aritmética dos coeficientes estomacal de jovens e adultos de L. varia (A), L. friderici (B), L. fasciatus (C) e L. trifasciatus (D). As setas indicam as rsepectivas médias. 
TABELA 2 - Amplitude total dos caracteres merísticos das espécies.

\begin{tabular}{|c|c|c|c|c|c|}
\hline Espécie & & $\begin{array}{l}\text { Laemolyta } \\
\text { varia }\end{array}$ & $\begin{array}{l}\text { Leporinus } \\
\text { friderici }\end{array}$ & $\begin{array}{l}\text { Leporinus } \\
\text { fasciatus }\end{array}$ & $\begin{array}{c}\text { Leporinus } \\
\text { trifasciatus }\end{array}$ \\
\hline $\mathrm{N} .^{\circ}$ de Exemplares & & 35 & 63 & 52 & 49 \\
\hline \multirow{9}{*}{$\begin{array}{l}\text { Escamas da linha } \\
\text { lateral }\end{array}$} & 38 & - & 8 & - & - \\
\hline & 39 & - & 18 & - & - \\
\hline & 40 & - & 35 & - & - \\
\hline & 41 & - & 2 & - & - \\
\hline & 42 & - & - & - & 11 \\
\hline & 43 & - & - & 24 & 36 \\
\hline & 44 & 4 & - & 26 & 2 \\
\hline & 45 & 14 & - & 2 & - \\
\hline & 46 & 17 & - & - & - \\
\hline \multirow{7}{*}{$\begin{array}{l}\text { Escamas acima e } \\
\text { (abaixo) da linha } \\
\text { lateral }\end{array}$} & 4,5 & - & $1(12)$ & - & - \\
\hline & 5 & (32) & $62(51)$ & - & $34(47)$ \\
\hline & 5,5 & ( 3 ) & - & - & $11(2)$ \\
\hline & 6 & 34 & - & (50) & 4 \\
\hline & 6,5 & 1 & - & $8(2)$ & - \\
\hline & 7 & - & - & 41 & - \\
\hline & 8 & - & - & 3 & - \\
\hline \multirow{4}{*}{$\begin{array}{ll}\text { Raios } & \text { Peitoral } \\
& \text { Dorsal } \\
& \text { Ventral } \\
& \text { Anal }\end{array}$} & & $i+15-17$ & $i+15-17$ & $i+15-17$ & $i+15-17$ \\
\hline & & $i i+10$ & $i i+10$ & $\mathrm{ii}+10$ & $\mathrm{i}+10$ \\
\hline & & $i+8$ & $\mathrm{i}+8$ & $i+8$ & $i+8$ \\
\hline & & $\mathrm{ii}+8$ & $\mathrm{ii}+8$ & $\mathrm{ii}+8$ & $\mathrm{ii}+8$ \\
\hline
\end{tabular}

\section{1 - Intestino (fig. 7 e 10).}

É um tubo cilíndrico, diminuindo fracamente de diâmetro do meio para o ânus; é formado por três dobras, a primeira descendo da porção pilórica até abaixo do estômago, daí subindo até aco nível do piloro e descendo novamente até o ânus. O coeficiente intestinal, isto é, a relação entre o tamanho do intestino e o tamanho padrão do peixe foi pouco menor nos jovens do que nos adultos e com média pouco maior em Laemolyta varia e L. trifasciatus $(1,25$ a 1,35$)$ do que nas duas outras espécies $(0,90$ a 1,21$)$.

\section{g - Padrão de colorido}

Laemolyta varia - (fig. 11). Em indivíduos com até cerca de $70 \mathrm{~mm}$ de comprimento padrão ocorrem de 12 a 16 faixas transversais escuras e estreitas, partindo da porção mais alta do dorso até as proximidades da linha lateral. Da ponta do focinho à base dos raios caudais mediancs ocorre uma faixa escura contínua, mais ou menos larga, pouco abaixo do nivel da linha lateral, terminada em uma mácula inconspícua na base da nadadeira caudal. O corpo é cinza-escuro prateado, um pouco esverdeado "in vitro", principalmente nas formas jovens. A partir deste tamanho, as faixas transversais estreitas tendem a desaparecer, acentuando-se aligumas que irão formar faixas mais largas nos indivíduos adultos: a primeira entre o opérculo e a nadadeira dorsal; a segunda, no começo da dorsal; a terceira entre a dorsal e a adiposa e a quarta, ao nível da adiposa. A faixa iongitudinal se acentua, permanecendo escura e mais larga nos indivíduos adultos.

Leporinus friderici - (fig. 12). Em indivíduos com até cerca de $100 \mathrm{~mm}$ de comprimento pedrão ocorrem 13 a 16 faixas transversais escuras, mais pronunciadas acima da linha la. tera!. Apresentam ainda três máculas arredondadas sobre a linha lateral: a $1^{\mathrm{a}}$ sob o nivel da nadadeira dorsal; a $2^{\text {a }}$ em frente à adiposa e a $3^{\mathrm{a}}$ na base dos raios caudais medianos. 0 corpu é de coloração castanho-escura. As nadadeiras ventral e anal apresentam-se com 


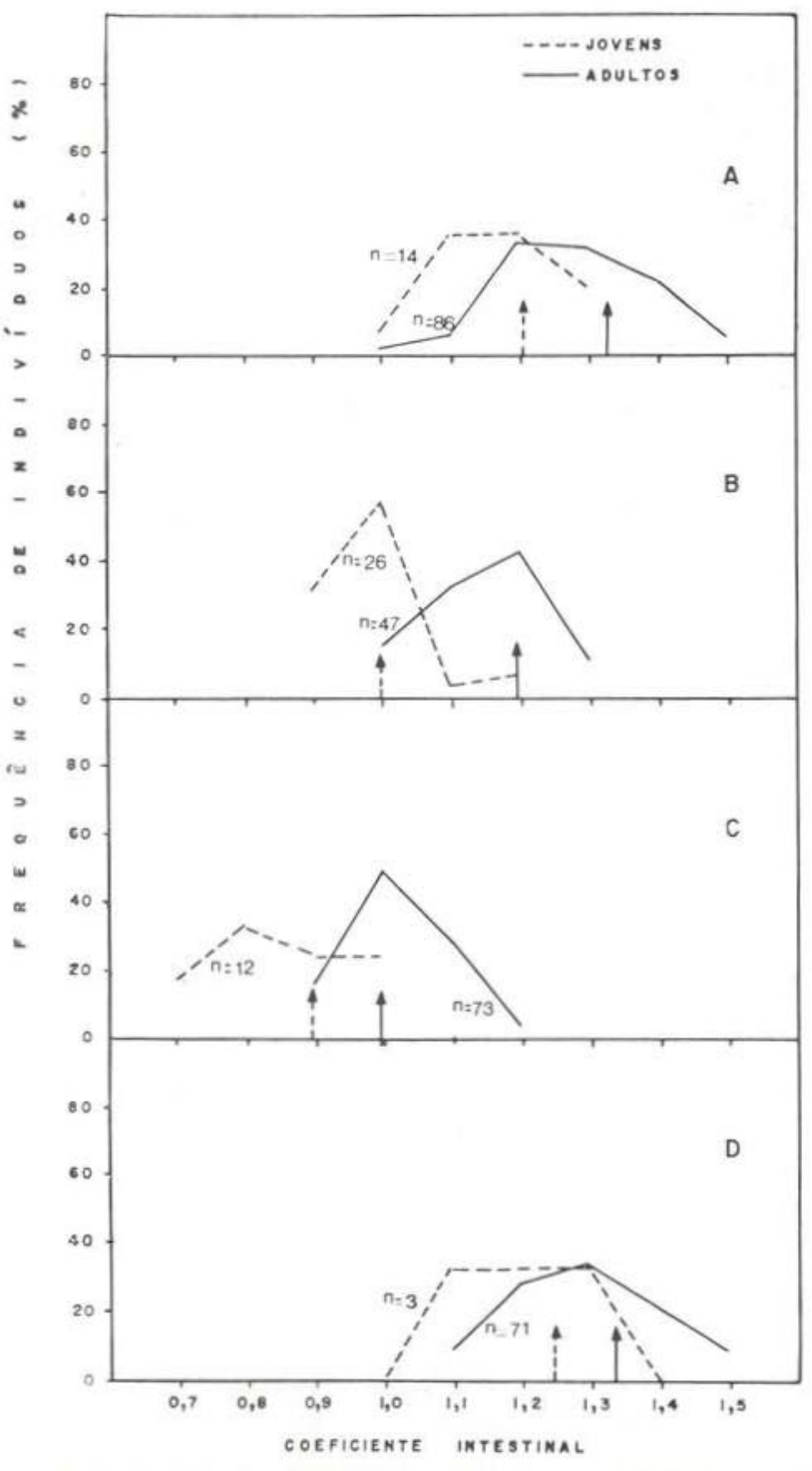

Fig. 10 - Distribuição dos valores do coeficiente intestinal em jovens e adultos de L. varia (A), L. friderici (B), L. fasciatus (C) e L. trifasciatus (D). As setas indicam as respectivas médias aritméticas.

manchas escuras na base. A adiposa é cinza com bordos pretos, formando um halo central. Além desse tamanho, as faixas transversais e o halo da adiposa tendem a desaparecer completamente, permanecendo e se acentuando as máculas arredondadas no meio do corpo.

Leporinus fasciatus - (fig. 13). Apresenta faixas verticais escuras sobre o corpo em individuos de todas as idades, variando apenas em número. Em indivíduos com até cerca de $20 \mathrm{~mm}$ de comprimento padrăc as faixas são em número de 8 , sendo a $1^{\text {a }}$ sobre o focinho (às vezes prolengando-se para baixo sobre o lábio inferior, formando um anel ao redor da boca); a $2^{\mathrm{a}}$ sobre o interorbital; a $3^{\mathrm{a}}$ sobre 0 opérculo; a $4^{\mathrm{a}}$ entre o opérculo e a nadadeiro dorsal; a $5^{\mathrm{a}}$ sob a dorsal; a $5^{\mathrm{a}}$ entre a dorsal e a adiposa; a $7^{\text {a }}$ ao nível da adiposa e a $8^{\text {a }}$. na base dos raios caudais, havendo na porção terminal da última uma mácula pequena, redonda e preta. Entre este tamanho e cerca de $100 \mathrm{~mm}$ de comprimento padrão, a $4^{\mathrm{a}}$ e $5^{\mathrm{a}}$ faixas se duplicam, elevando-se para 10 e desaparece a mácula preta na base caudal; as manchas escuras na base das nadadeiras dorsal, ventral e anal tendem a desaparecer. Acima deste tamanho a $8^{\mathrm{a}}$ a $9^{\mathrm{a}}$ bandas também se duplicam, elevando-se para 12 e ocasionalmente 13 , assim distribuídas: as 3 primeiras sobre a cabeça nas mesmas posições relativas; a $4^{\mathrm{a}}$ e $5^{\mathrm{a}}$ entre 0 opérculo e a dorsal a $6^{\mathrm{a}} \mathrm{sob}$ a dorsal; a $7^{\mathrm{a}}, 8^{\mathrm{a}}$ e $9^{\mathrm{a}}$, entre a dorsal e a adiposa; a $10^{\text {a }}$ ao nível da adiposa; a $11^{\text {a }}$ entre a adiposa e a caudal e a $12^{\text {a }}$ (e ocasionalmente a $13^{\text {a }}$ ) na base do pedúnculo caudal: 0 corpo em todas as idades apresentam-se com coloração amarela, sendo nos adultos, "in vitro", alaranjado na região opercular.

Leporinus trifasciatus - (fig. 14). Em indivíduos com até cerca de $90 \mathrm{~mm}$ de comprimento padrão, ocorrem 14 a 16 faixas transversais escuras alongadas ou $\in \mathrm{m}$ forma de $X$, $\mathrm{Y}$ sobre o corpo, sendo mais pronunciadas acima da linha lateral e três máculas arredondadas escuras na linha mediana do corpo: a $1^{\text {a }}$ ao nivel da nadadeira dorsal; a $2^{\mathrm{a}}$, entre a dorsal e a adiposa e a $3^{a}$ na base do pedúnculo caudal. O corpo é de cor cinz̄a-escura. A par-

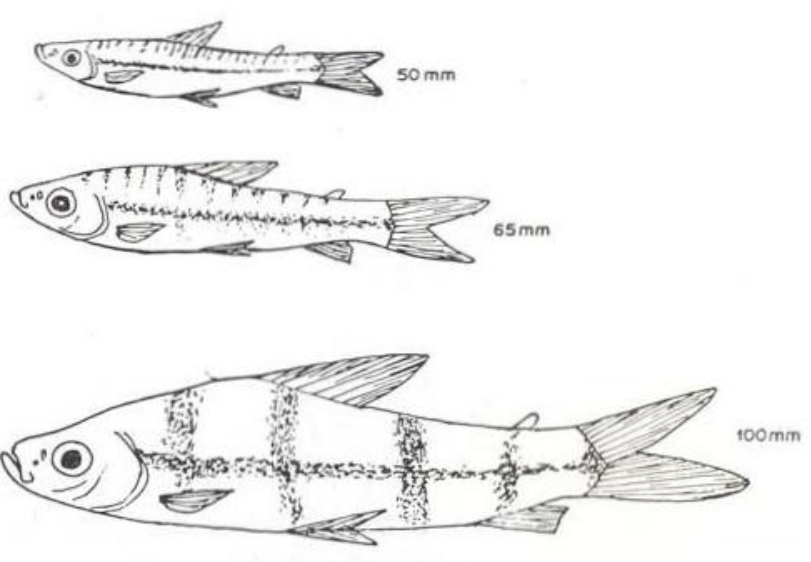

Fig. 11 - Variação ontogenética do padrão de colorido em Laemolyta varia. 
tir deste tamanho as máculas tendem a desaparecer exceto as da região pós-opecular que se acentuam formando uma faixa larga. As $1^{\text {a }}$ e $2^{\text {a }}$ máculas se alongam verticalmente, formando faixas escuras sobre o corpo, permanecendo e se acentuando a $3^{\text {a }}$ mácula na base do pedúnculo caudal. Em indivíduos adultos, a região opercular é alaranjada "in vitro", ficando clara quando o peixe é preservado.

\section{ALIMENTAÇÃo}

Para o estudo da alimentação, foram analisaoos 135 indivíduos de Laemolyta varia; 68 de $L \in$ porinus friderici; 100 de $L$. fasciatus e 114 de $L$. trifasciatus. Os Gr totais foram baixos para as quatro espécies $(0,99$ a 1,99$)$. Na estação baixa, ocorreram os maiores valores do $\mathrm{Gr}$, sendo que os menores se deram na estação elevada (tab. 3).
Quanto à natureza do alimiento das espé. cies analisadas, observa-se que não variou pronunciadamente nas estações nem entre as formas jovens e adultas. As análises qualitativa e quantitativa mostram uma grande similaridade de ocorrência dos ítens, indicando que os alimentos mais freqüentes são também os mais abundantes, (fig. 15 e 16). Apesar de apresentar uma alta percentagem em todas as espécies e em todas as estações, o item detritos não parece indicar uma fonte alimentar especifica mas o resultado da digestão parcial dos outros ítens encontrados.

Os alimentos básicos de $L$. varia foram materiai vegetal, "coarse-litter" e ninfas de insetos (Diptera e Efemeroptera), sendo notória a presença de Esponja na estação alta. Leporinus friderici apresentou um regime alimentar misto composto de material de origem

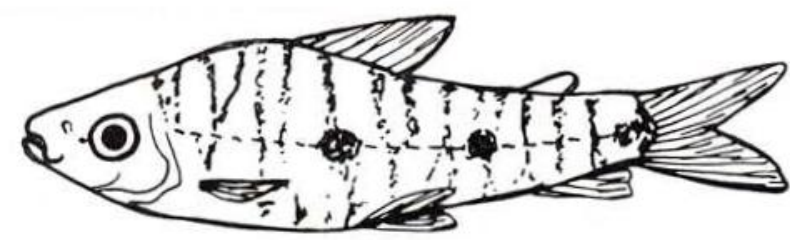

$60 \mathrm{~mm}$
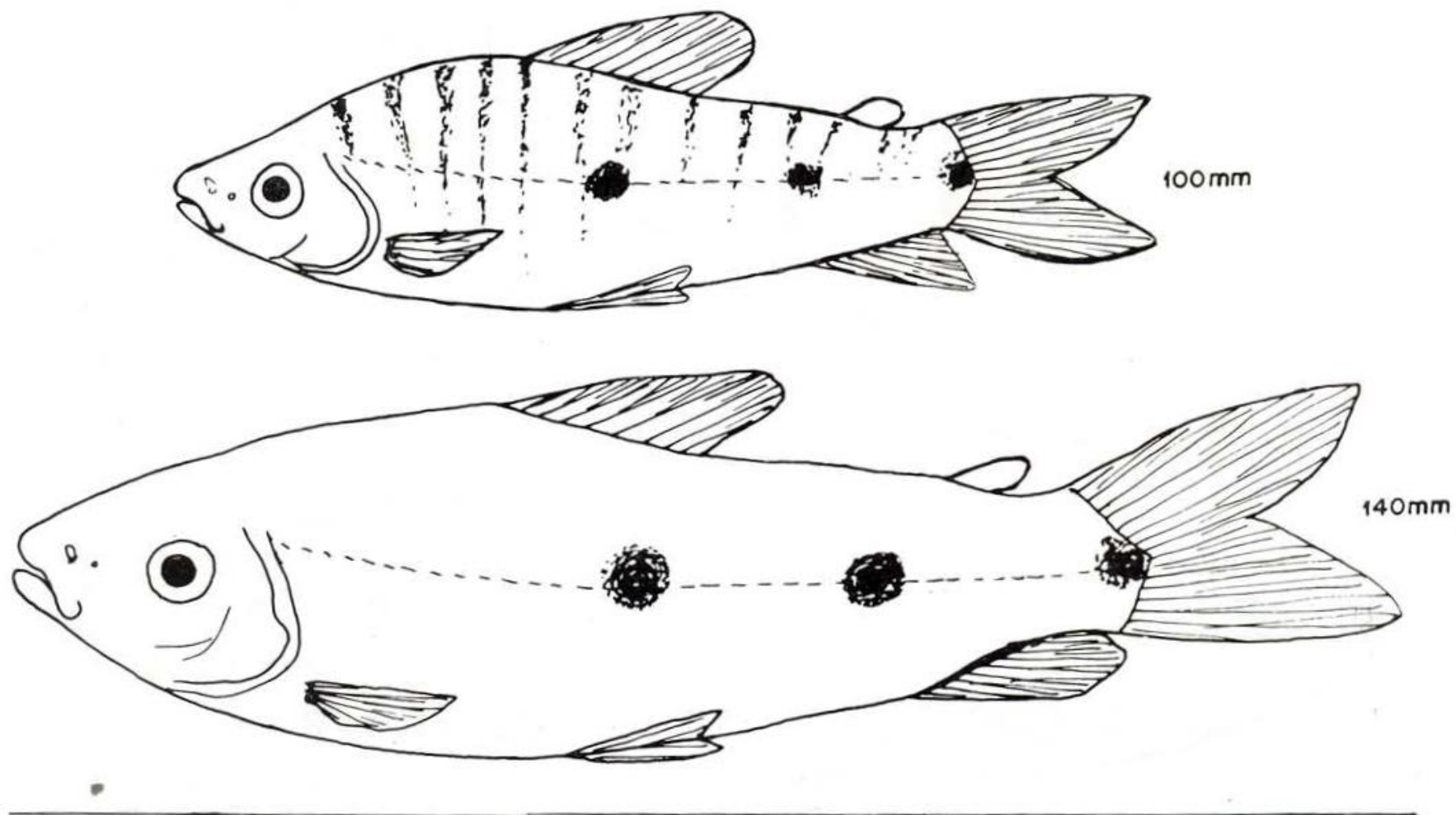

Fig. 12 - Variação ontogenética do padrão de colorido em Leporinus friderici. 


\section{Uintion}
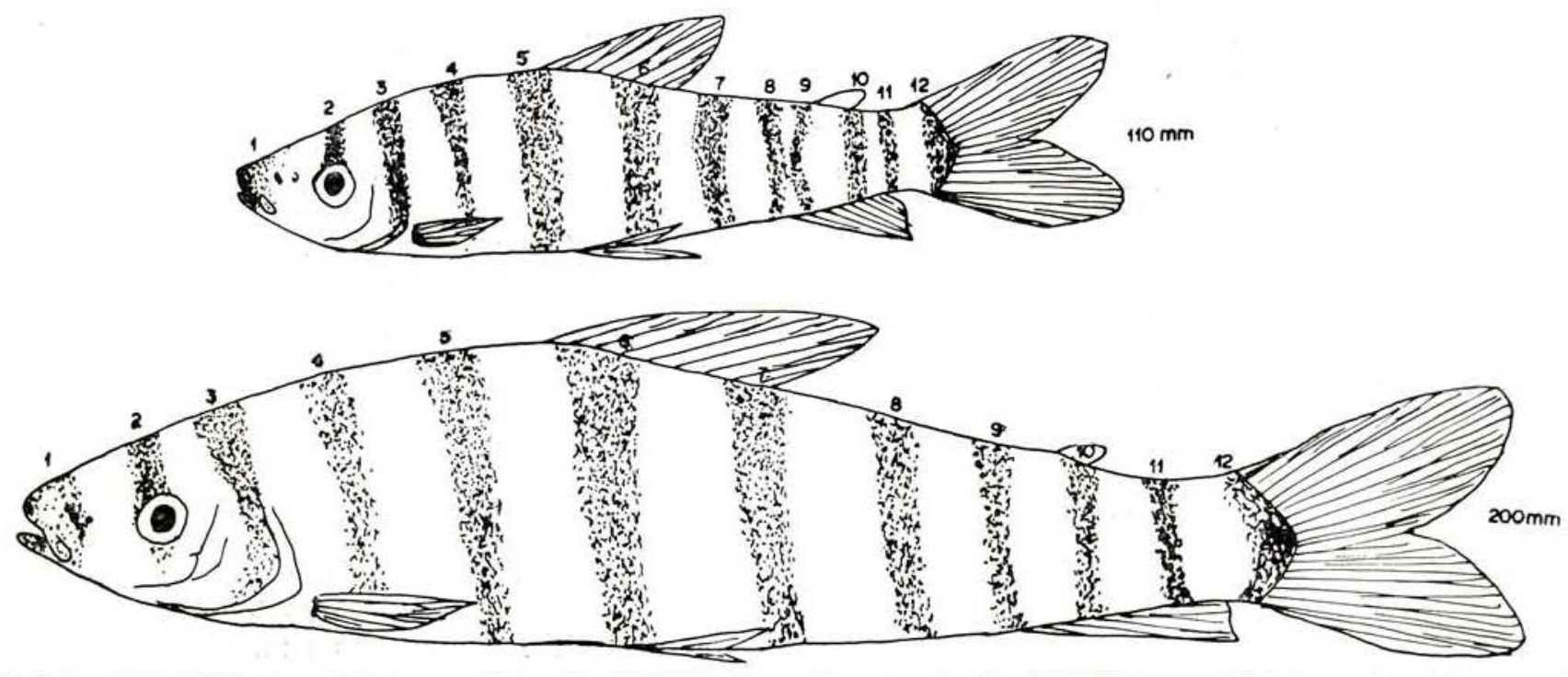

Fig. 13 - Variação ontogenética do padrão de colorido em Leporinus fasciatus.
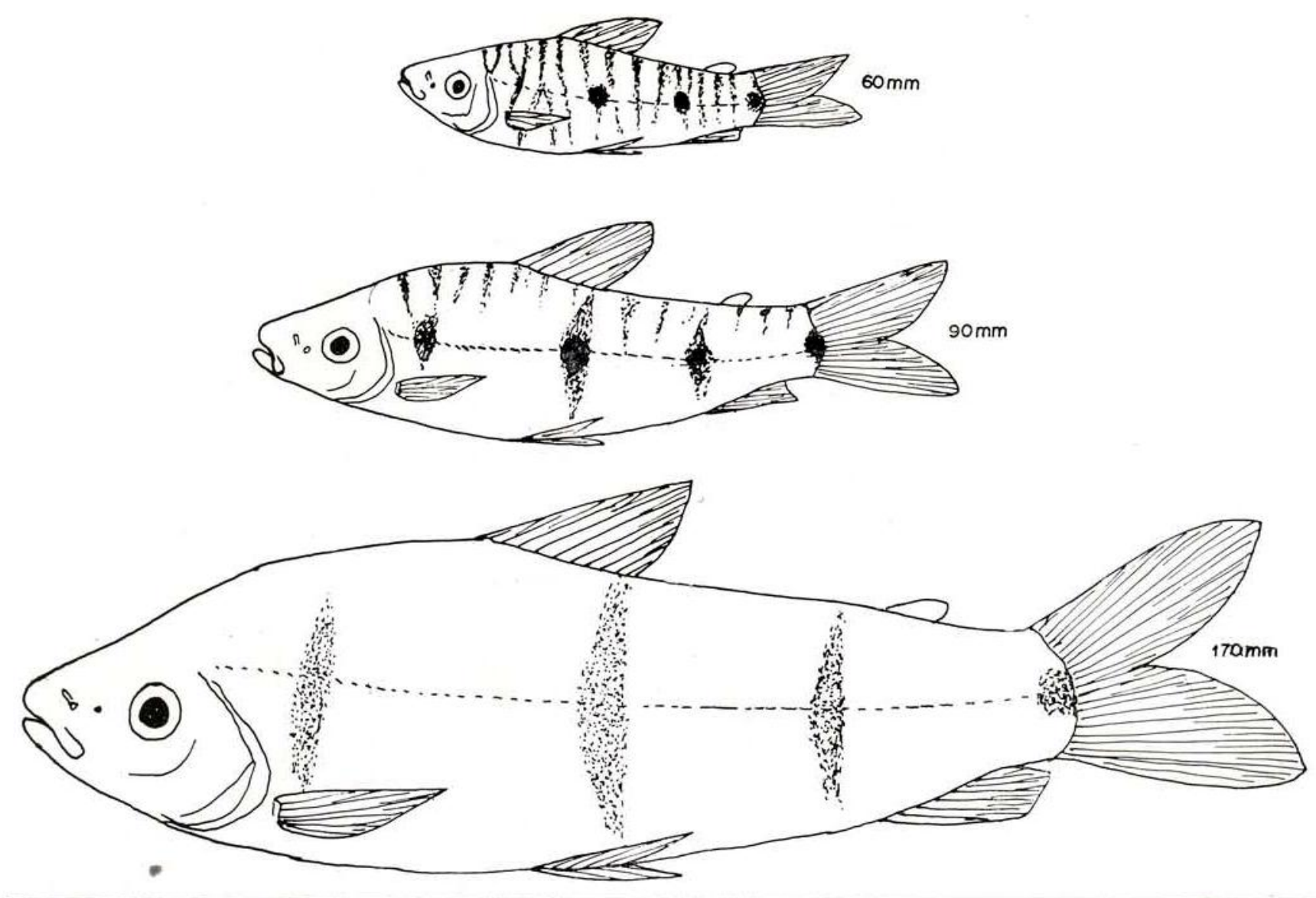

Fig. 14 - Variação ontogenética do padrão de colorido em Leporinus trifasciatus. 


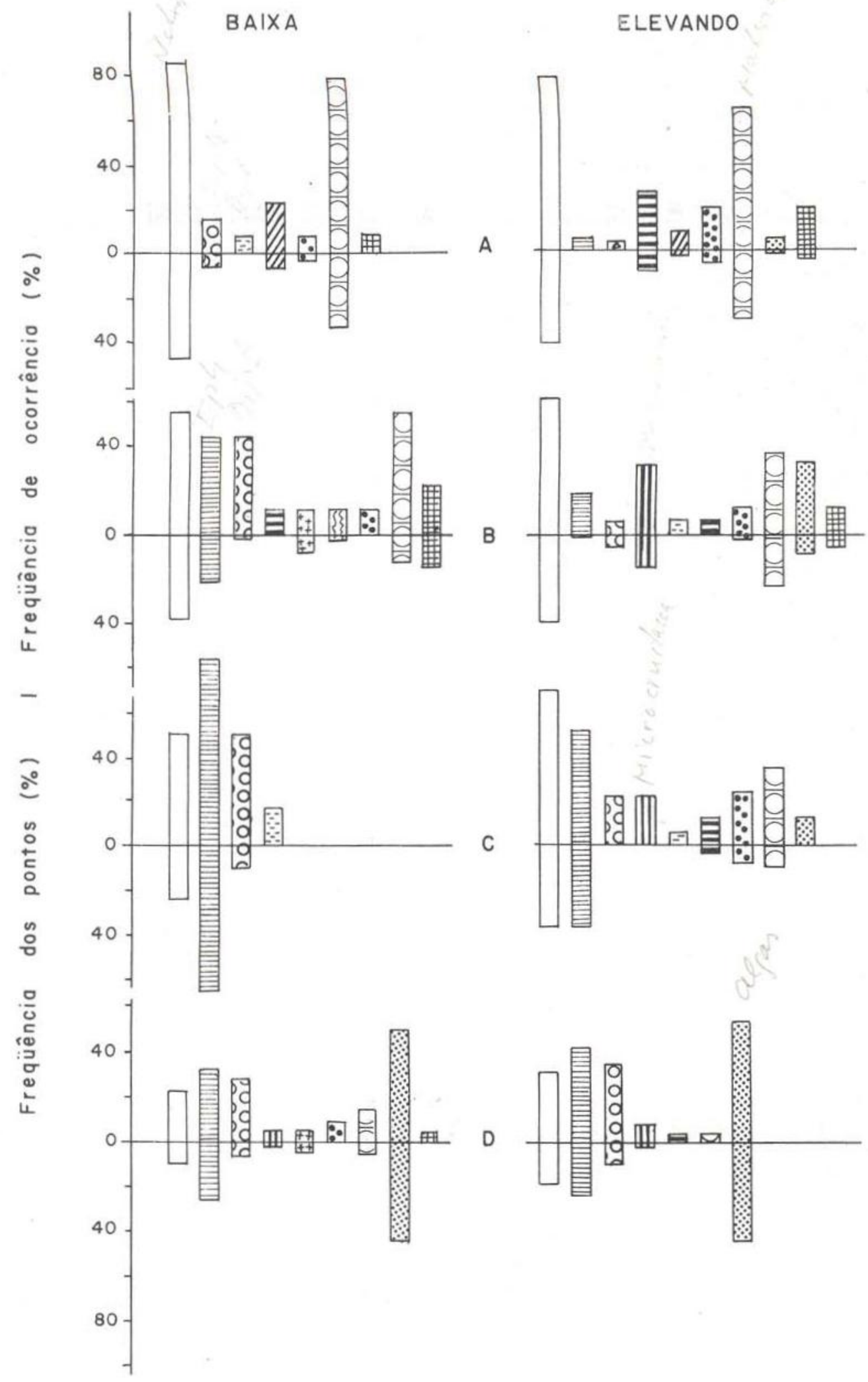

Fig. 15a - Anélise qualitativa e quantitativa dos itens alimentares em L. varia (A), L. friderici (B), L. fasciatus (C) e L. trifasciatus (D), nas estaçōes "Baixa" e "Elevando". 


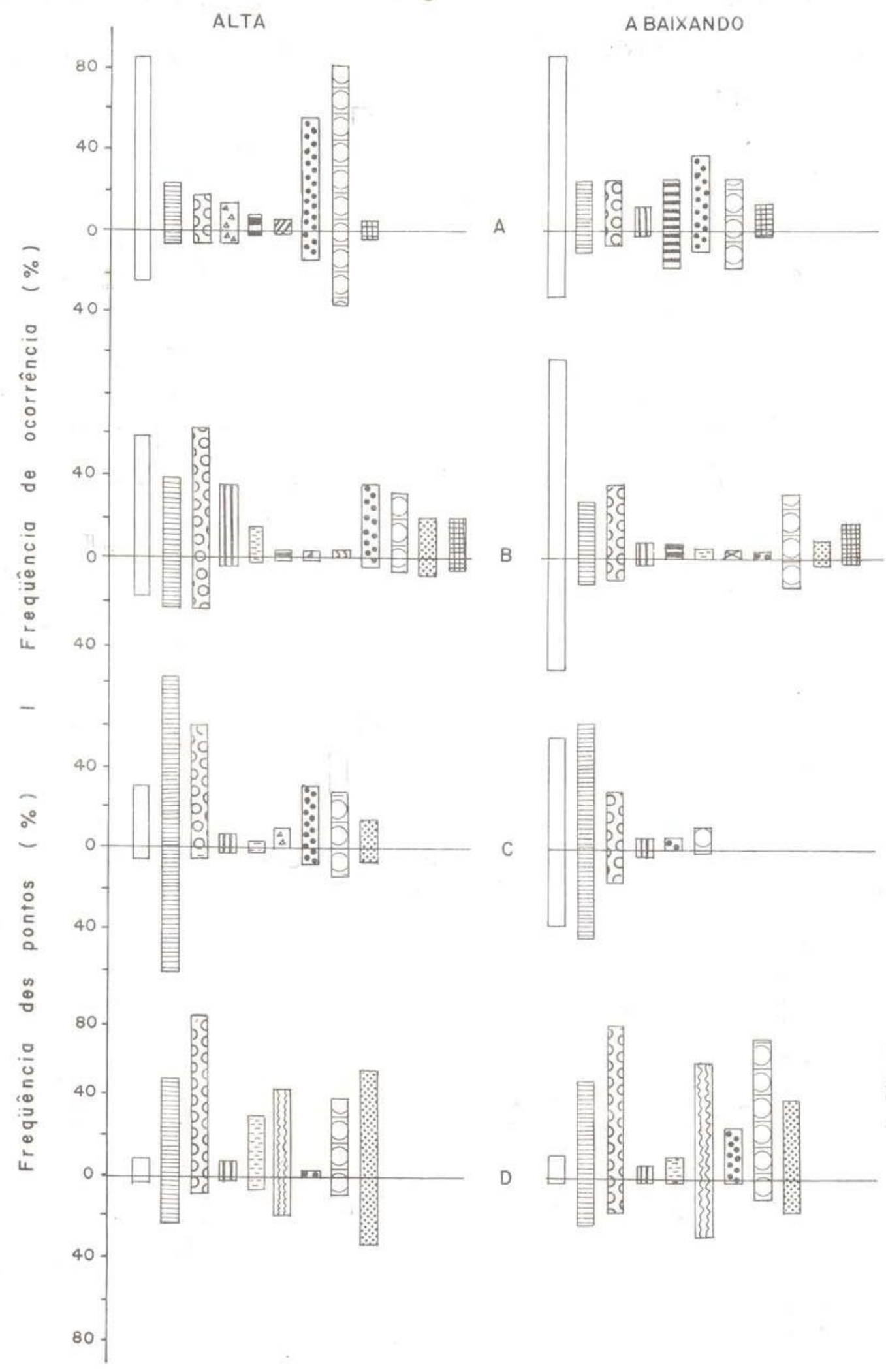

Fig. 15b - Análise qualitativa e quantitativa dos itens alimentares em L. varia (A), L. friderici (B), L. fasciatus (C) e L. trifasciatus (D) nas estaçōes "Alta" e "Abaixando". 
TABELA 3 - Distribuição dos pontos atribuidos e dos graus médios de repleção das espécies nas diferentes "es. taçōes".

\begin{tabular}{|c|c|c|c|c|c|c|}
\hline Pontos & Estação & Alta & Abaixando & Baixa & Elevando & Total \\
\hline
\end{tabular}

\begin{tabular}{|c|c|c|c|c|c|}
\hline \multicolumn{6}{|c|}{ Laemolyta varia } \\
\hline 0 & 6 & 1 & 1 & 31 & 39 \\
\hline 0,5 & 14 & 2 & 3 & 38 & 57 \\
\hline 1 & 3 & 1 & - & 8 & 12 \\
\hline 2 & - & 3 & 1 & 2 & 6 \\
\hline 3 & 4 & 2 & 5 & 4 & 15 \\
\hline 4 & - & - & 4 & 2 & 6 \\
\hline Total & 27 & 9 & 14 & 85 & 135 \\
\hline $\mathrm{Gr}$ & 0,81 & 1,55 & 2,46 & 0,60 & 0,90 \\
\hline
\end{tabular}

\begin{tabular}{|c|c|c|c|c|c|}
\hline & & Leporinus & friderici & & \\
\hline 0 & - & 3 & - & 9 & 12 \\
\hline 0.5 & 1 & 10 & 1 & 8 & 20 \\
\hline 1 & 4 & 4 & - & - & 8 \\
\hline 2 & 4 & 5 & 1 & 1 & 11 \\
\hline 3 & - & 3 & - & 2 & 5 \\
\hline 4 & 3 & 2 & 5 & 2 & 12 \\
\hline Total & 12 & 27 & 7 & 22 & 68 \\
\hline $\mathrm{Gr}$ & 2,04 & 1,33 & 3,21 & 0,90 & 1,51 \\
\hline
\end{tabular}

\begin{tabular}{|c|c|c|c|c|c|}
\hline & & Leporinus & fasciatus & & \\
\hline 0 & 15 & 6 & 1 & 10 & 32 \\
\hline 0,5 & 10 & 9 & 3 & 14 & 36 \\
\hline 1 & 3 & 1 & - & 3 & 7 \\
\hline 2 & 4 & 3 & 1 & - & 8 \\
\hline 3 & 7 & - & 1 & - & 8 \\
\hline 4 & 4 & 4 & 1 & - & 9 \\
\hline Total & 43 & 23 & 7 & 27 & 100 \\
\hline Gr & 1,23 & 1,19 & 1.50 & 0,37 & 1,01 \\
\hline \multicolumn{6}{|c|}{ Leporinus trifasciatus } \\
\hline 0 & 4 & 4 & 5 & 1 & 14 \\
\hline 0,5 & 3 & 5 & 3 & 8 & 19 \\
\hline 1 & 5 & 2 & 8 & 1 & 16 \\
\hline 2 & 6 & 7 & 3 & 1 & 17 \\
\hline 3 & 5 & 5 & 5 & 9 & 24 \\
\hline 4 & 5 & 9 & 2 & 8 & 24 \\
\hline - $T$ & 28 & 32 & 26 & 28 & 114 \\
\hline $\mathrm{Gr}$ & 1,91 & 2,17 & 1,48 & 2,35 & 1,99 \\
\hline
\end{tabular}

Caracterização... 
animal (ninfas de Efemeroptera e Diptera) e vegetal (material vegetal e algis filamentosas) - Leporinus fasciatus teve como fonte alimentar básica os itens de origem animal (ninfas de Efemeroptera e de Diptera) apresentando em média um espectro de ítens alimentares nas quatro estações menor que o das demais espéries. Leporinus trifasciátus apresentou uma dieta alimentar predominantemente à base de material animal (ninfas de Efemeroptera e Diptera e de Moluscos) e vegetal (frutos e sementes) mais ou menos nas mesmas propor. ções.

Os coeficientes de sobreposição alimen. tar (fig. 17) foram altos (acima de 0,3 ou seja $30 \%$ ) entre todas as quatro espécies e em to. das as estações, sendo maiores nas estações

A

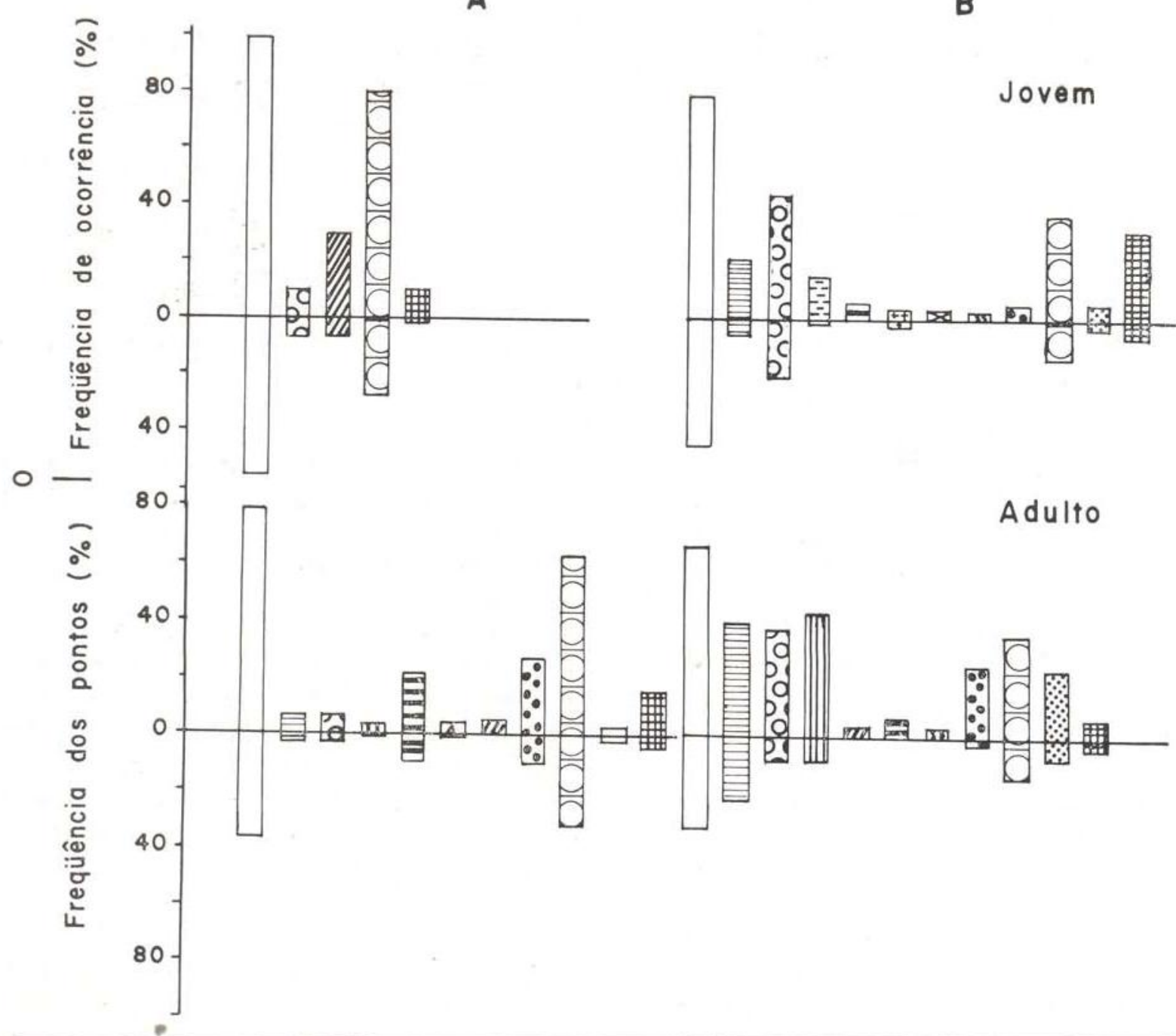

alta e elevando e menores na estação baixa. L. Varia e L. friderici apresentaram os maio res coeficientes de sobreposição (acima de $70 \%$ ) em todas as estações, sendo mais ou menos uniforme nas outras espécies nas dife. rentes estações.

Comparados com os coeficientes encontra. dos para outras espécies estudadas anterior. mente (Santos, 1981) observa-se uma grande variação dos seus valores (abaixo de $30 \%$ e acima de $70 \%$ ), sendo maiores nas espécies congêneres (fig. 18).

REPRODUÇÃo

Para o estudo da reprodução foram anali. sados 266 individuos de L. varia; 36 de L. fri.
B 

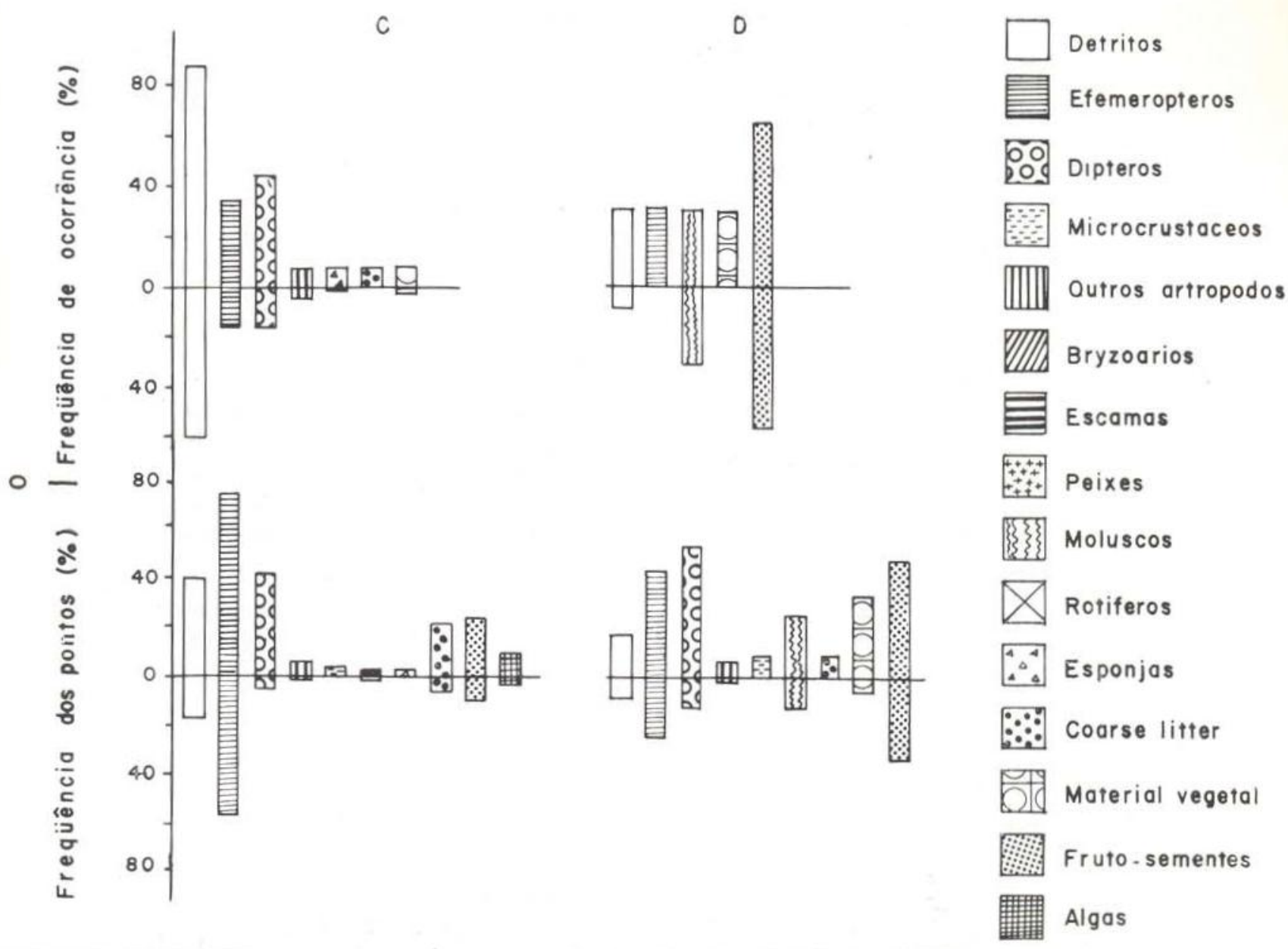

Fig. 16b - Análise qualitativa e quantitativa dos ítens alımentares de jovens e adultos de Leporinus fasciatus (C) e L. trifas ciatus (D).

derici; 139 de L. fasciatus e 127 de L. trifasciatus (tab. 5). Os estágios gonadais considera. dos e suas características correspondentes, nas quatro espécies estudadas, encontram-se descritos na tabela 4 .

O maior e menor graus médios de maturação (tab. 5 fig. 19) se deram nas estações "elevando" e "abaixando", respectivamente, para todas as espécies, exceto $L$. trifasciatus. Nesta espécie o maior e menor graus médios de maturação se deram nas estações "baixa", e "aita", respectivamente. Ao contrário das demais espécies estudadas, L. trifasciatus não apresentou $\mathrm{Gr}$ igual a 2, correspondente a $100 \%$ de indivíduos em estágio de repouso absoluto, mas sempre acima desse valor.

De acordo com a tab. 5 fig. 20, o estágic II é dominante nas estações "abaixando"; o III e IV, nas estações "baixa” e elevando o V e VI, nas estaçōes elevando em todas as espécies, exceto em L. trifasciatus em que o estágio II é mais freqüente na estação alta; o III e IV, na abaixando e baixa e o VI, na alta. Não foram encontrados indivíduos dessa espécie com gônadas no estágio $\mathrm{V}$.

A variação do comprimento padrão de indivíduos adultos das espécies em ordem crescente foi de 15,5 a $24,5 \mathrm{~cm}$ em $L$. varia; 18,5 a $27,5 \mathrm{~cm}$ em L. friderici; 18,5 a 30,5 em L. fas. ciatus e 18,5 a 33,5 em L. trifasciatus, observando-se que as fêmeas das quatro espécies são proporcionalmente maiores e alcançam maiores tamanhos que os machos correspondentes (fig. 21-I).

O "sex-ratio" ou freqüência relativa de machos e fêmeas mostra que o número de fêmea foi maior que o de machos, exceto em $L$. trifasciatus em que os dois sexos ocorreram mais ou menos nas mesmas proporções. (fig. $21-(1)$. 
O tamanho médio do início de maturação sexual dos indivíduos das três primeiras espécies está em torno de 140 a $150 \mathrm{~mm}$. sendo maior (cerca de $180 \mathrm{~mm}$ ) em indivíduos de $L$. trifasciatus (fig. 22).

TABEL.A 4 - Estágios gonadais, suas principais caracteristicas macroscópicas, por sexo, nas espécies estudadas.

\begin{tabular}{|c|c|c|}
\hline $\begin{array}{l}\text { Estágios } \\
\text { gonadais }\end{array}$ & Sexos & Características \\
\hline \multicolumn{3}{|l|}{ 1-Juvenil } \\
\hline & - & $\begin{array}{l}\text { gônadas muito finas, redondas, } \\
\text { transparentes, rosa-claro; sexos } \\
\text { indistintos a olho nu. }\end{array}$ \\
\hline \multirow{2}{*}{ II - Repouso } & M & $\begin{array}{l}\text { gônadas finas, redondas, trans- } \\
\text { parentes, rosa a vermelho. }\end{array}$ \\
\hline & $\mathrm{F}$ & $\begin{array}{l}\text { gônadas achatadas ventralmen- } \\
\text { te e arredondadas dorsalmente, } \\
\text { transparentes, amarelas a ró- } \\
\text { seas; sem óvulos visíveis a } \\
\text { olho nu. }\end{array}$ \\
\hline
\end{tabular}

M gônadas mais grossas e arredondadas, não transparentes, róseas a leitosas; o sêmen não flui quando se corta e pressiona a gônada.

III - Maturação

F gônadas achatadas ventralmen. te e arredondadas dorsalmente, não transparentes, amarelas; alguns óvulos visíveis a olho nu.

M gônadas grossas, arredondadas e enrugadas, róseas a leitosas; o sêmen flui quando se corta e pressiona a gônada mas não quando se faz pressão sobre o abdomen do peixe.

IV - Maduro

F gônadas entumescidas, grandes, achatadas ventralmente e arredondadas dorsalmente, totalmente tomadas por óvulos visíveis a olho nu, não sofrendo extrusão quando se faz leve pressão no ventre do peixe
TABELA $4-$ (Continuação).

$\begin{array}{ll}\text { Estágios } & \\ \text { gonadais } \quad \text { Sexos } & \text { Características }\end{array}$

M gônadas entumescidas, arredondadas e rugosas, cinza a leitosas, o sêmen flui quando se faz leve pressão no ventre do peixe.

V-Desova

F gônadas entumescidas, ocupando quase toda a cavidade abdominal, cinzas; os óvulos fluem numa matriz gelatinosa quando se faz leve pressão no abdomen do peixe.

M gônadas arredondadas a achatadas, flácidas, vermelhas, "inflamadas".

VI-Pós-desova

F gônadas achatadas, flácidas, com alguns óvulos visíveis a olho nu, vermelhas, "inflama. das".

\section{DISCUSSÃO E CONCLUSÕES}

A familia Anostomidae é constituída por 90 a 100 espécies, sendo que cerca da metade desso número ocorre na Bacia Amazôniç (Géry, 1977). No Janauacá, típico representante de lagos de várzea, onde se espera en contrar a maior riqueza e diversidade animal nas águas amazônicas, foram encontradas apenas 15 espécies deste grupo de peixes. No alto rio Negro foi encontrado um número igual ou maior de espécies (Goulding, comunicação pesscal), sendo que no baixo rio Negro foram encontradas 8 ↔spécies desta família, e onde as espécies predominantes foram as mais raras ou näo ocorreram no Janauacá (Santos em preparação) .

Apenas duas espécies de anostomídeos dominam o lago Janauacá: Schizodon fasciatus $(54,3 \%)$ e Rhytiodus microlepis $(19,5 \%)$. Juntamente com Laemolyta varia $(15,2 \%)$ somam $89 \%$ dos indivíduos amostrados. ficando as demais 12 espécies com apenas $11 \%$ dos indivíduos da área. 
O aumento da freqüência relativa de ocorrência e a dominância de $L$. varia na estação "elevando" deveu-se ao fato de esta espécie ter-se deslocado das cabeceiras do lago (onde parece normalmente viver o grosso das populações) para a entrada do lago, sob influência da água "nova" do rio Solimões, para desovar. Pelo fato de todas as coletas terem sido realizadas apenas da entrada ao meio do lago, esta espécie teve uma freqüência de ocorrência baixa e uniforme nas demais estações, nesta área.

\section{$B A \mid X A$}
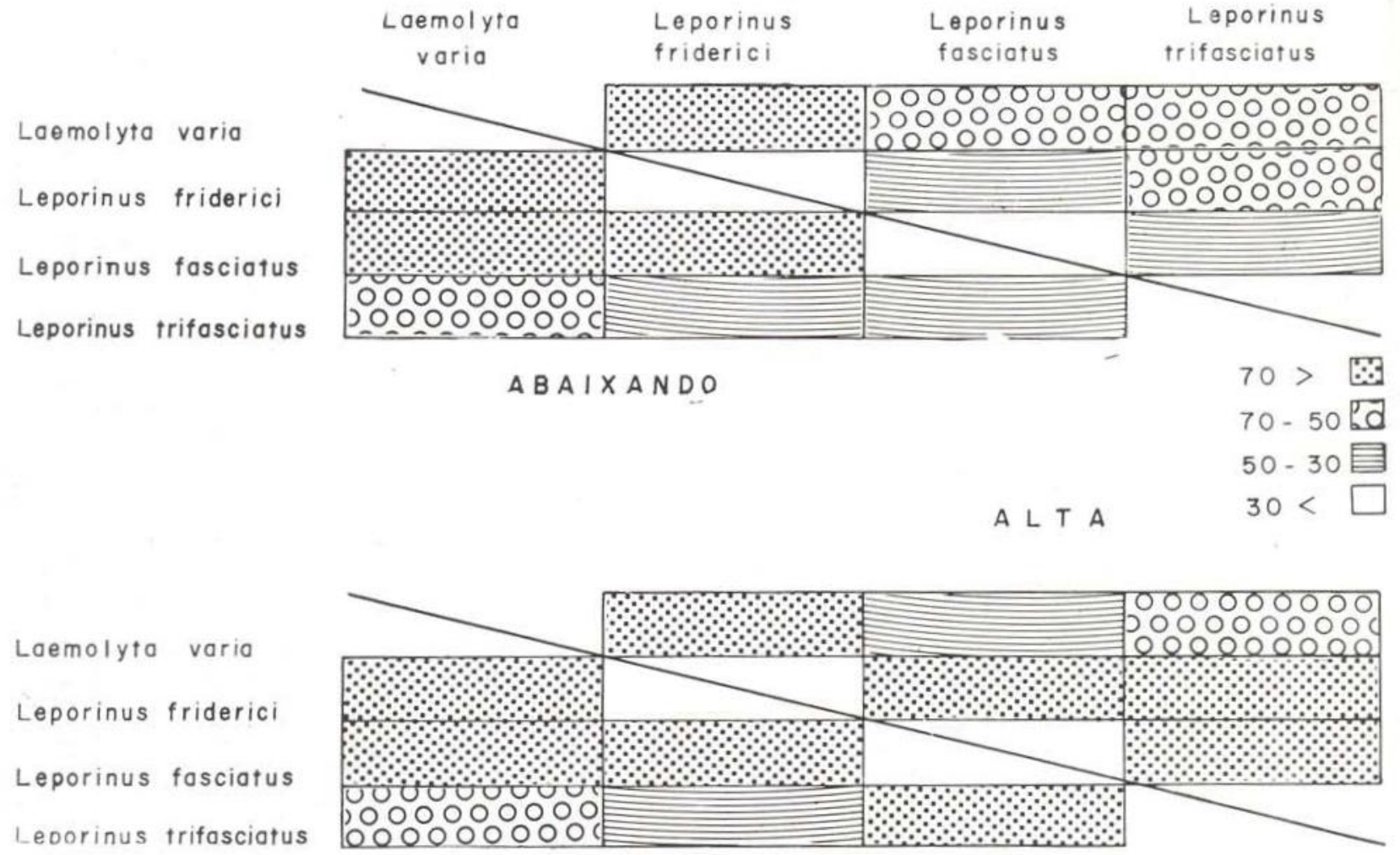

ELE VANDO

Fig. 17 - Coeficientes de sobreposição alimentar entre as quatro espécies, nas diferentes "estaçōes"

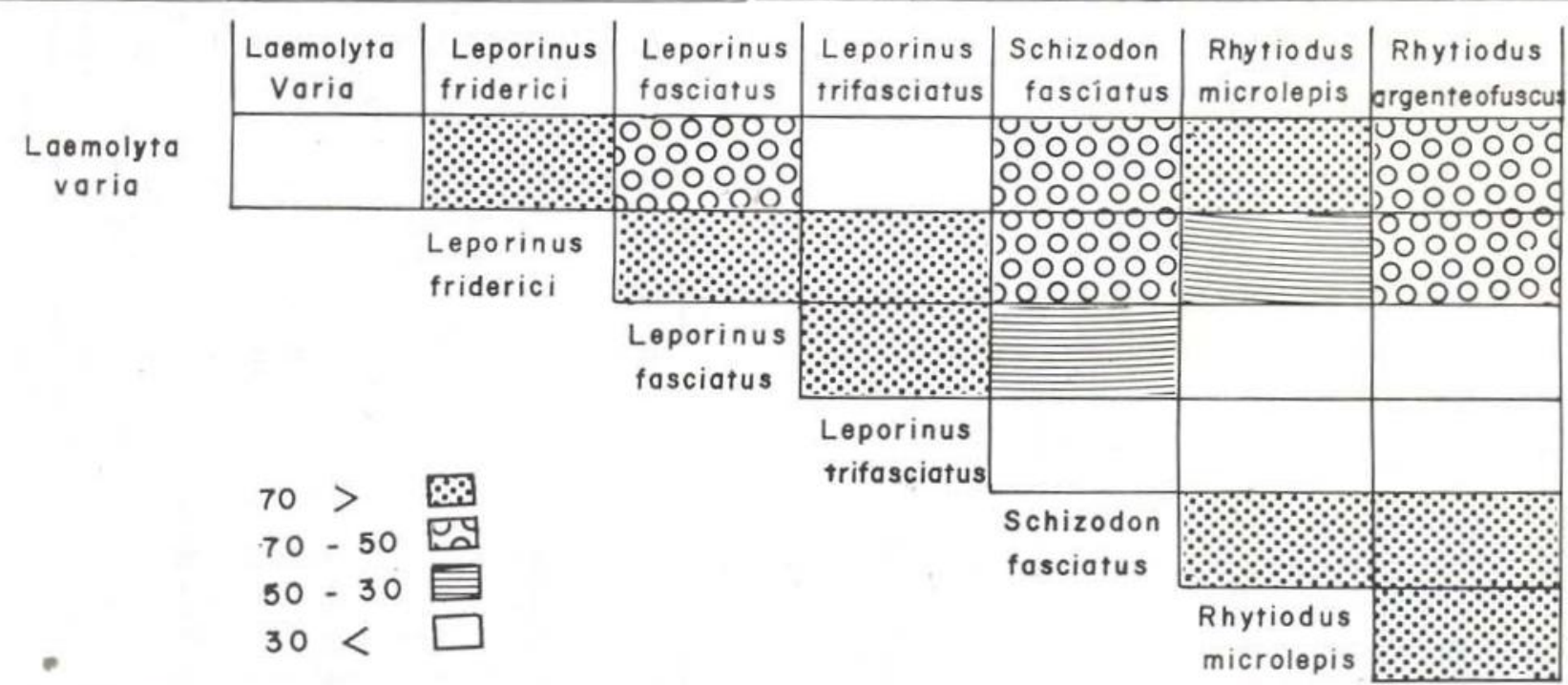

Fig. 18 - Coeficientes de sobreposição alimentar entre as espécies de Anostomidae do lago Janauacá, já estudadas. 
TABELA 5 - Frequêencias absoluta e relativa dos estágios gonadais e graus médios de maturação (Gm) das quatro espécies estudadas, nas diferentes "esta çốes".

\begin{tabular}{|c|c|c|c|c|c|c|c|c|c|c|c|}
\hline \multirow{3}{*}{$\begin{array}{c}\text { Espécie } \\
\|\end{array}$} & \multirow{3}{*}{$\begin{array}{c}\begin{array}{c}\text { Estágio } \\
\text { gonadal }\end{array} \\
\text { II }\end{array}$} & \multicolumn{10}{|c|}{ Estação } \\
\hline & & \multicolumn{2}{|c|}{ Alta } & \multicolumn{2}{|c|}{ Abaixando } & \multicolumn{2}{|c|}{ Baixa } & \multicolumn{2}{|c|}{ Elevando } & \multicolumn{2}{|c|}{ Total } \\
\hline & & 57 & $(82,6)$ & 20 & $(100,0)$ & 4 & $(80,0)$ & 3 & $(1,7)$ & 84 & $(31,6)$ \\
\hline \multirow{6}{*}{ Laemolyta varia } & III & 1 & $(1,5)$ & - & - & 1 & $(20,0)$ & 1 & $(0,6)$ & 3 & $(1,1)$ \\
\hline & IV & 1 & $(1,5)$ & - & - & - & - & 36 & $(20,9)$ & 37 & $(13,9)$ \\
\hline & $\mathrm{v}$ & 7 & $(10,1)$ & - & - & - & - & 131 & $(76,2)$ & 138 & $(51,9)$ \\
\hline & VI & 3 & $(4,3)$ & - & - & - & - & 1 & $(0,6)$ & 4 & $(1,5)$ \\
\hline & Total & 69 & $(100,0)$ & 20 & $(100,0)$ & 5 & $(100,0)$ & 172 & $(100,0)$ & 266 & $(100,0)$ \\
\hline & $\mathrm{Gm}$ & \multicolumn{2}{|c|}{2,52} & \multicolumn{2}{|c|}{2,00} & \multicolumn{2}{|c|}{2,20} & \multicolumn{2}{|c|}{4,73} & \multicolumn{2}{|c|}{3,91} \\
\hline \multirow{7}{*}{ Leporinus friderici } & II & 8 & $(80,0)$ & 4 & $(100,0)$ & - & - & 3 & $(15,8)$ & 15 & $(41,7)$ \\
\hline & III & 2 & $(20,0)$ & - & - & - & - & - & - & 2 & $(5,5)$ \\
\hline & IV & - & - & - & - & 1 & $(33,3)$ & 2 & $(10,5)$ & 3 & $(8,3)$ \\
\hline & V & - & - & - & - & 2 & $(66,6)$ & 13 & $(68,4)$ & 15 & $(41,7)$ \\
\hline & $\mathrm{VI}$ & - & - & - & - & 一 & - & 1 & $(5,3)$ & 1 & $(2,8)$ \\
\hline & Total & 10 & $(100,0)$ & 4 & $(100,0)$ & 3 & $(99,9)$ & 19 & $(100,0)$ & 36 & $(100,0)$ \\
\hline & $\mathrm{Gm}$ & \multicolumn{2}{|c|}{2,20} & \multicolumn{2}{|c|}{2,00} & \multicolumn{2}{|c|}{4,67} & \multicolumn{2}{|c|}{4,47} & \multicolumn{2}{|c|}{3,58} \\
\hline \multirow{7}{*}{ Leporinus fasciatus } & II & 63 & $(70,8)$ & 17 & $(100,0)$ & 6 & $(100,0)$ & 3 & $(11,1)$ & 89 & $(64,0)$ \\
\hline & III & - & - & - & - & - & - & - & - & - & - \\
\hline & IV & 7 & $(7,9)$ & - & - & - & - & 12 & $(44,4)$ & 19 & $(13,7)$ \\
\hline & V & 8 & $(9,0)$ & - & - & - & - & 8 & $(29,6)$ & 16 & $(11,5)$ \\
\hline & VI & 11 & $(12,3)$ & - & 一 & 一 & - & 4 & $(14,8)$ & 15 & $(10,8)$ \\
\hline & Total & 89 & $(100,0)$ & 17 & $(100,0)$ & 6 & $(100,0)$ & 27 & $(99,9)$ & 139 & $(100,0)$ \\
\hline & $\mathrm{Gm}$ & \multicolumn{2}{|c|}{2,92} & \multicolumn{2}{|c|}{2,00} & \multicolumn{2}{|c|}{2,00} & \multicolumn{2}{|c|}{4,37} & \multicolumn{2}{|c|}{3,09} \\
\hline \multirow{7}{*}{ Leporinus trifasciatus } & II & 29 & $(93,5)$ & 17 & $(41,5)$ & 10 & $(37,0)$ & 24 & $(85,7)$ & 80 & $(63,0)$ \\
\hline & III & - & - & 24 & $(58,5)$ & 9 & $(33,3)$ & - & - & 33 & $(26,0)$ \\
\hline & IV & - & - & - & - & 8 & $(29,6)$ & - & - & 8 & $(6,3)$ \\
\hline & v & - & - & - & - & - & - & - & - & - & - \\
\hline & VI & 2 & $(6,5)$ & - & - & - & - & 4 & $(14,3)$ & 6 & $(4,7)$ \\
\hline & Total & 31 & $(100,0)$ & 41 & $(100,0)$ & 27 & $(99,9)$ & 28 & $(100,0)$ & 127 & $(100,0)$ \\
\hline & $\mathrm{Gm}$ & \multicolumn{2}{|c|}{2,25} & & & & & & & & \\
\hline
\end{tabular}


A redução da freqüência do $S$. fasciatus na estação alta parece ter-se dado em conseqüência さ̉e sua migração da área litural do lago para os igapós ou matas alagadas principalmente em busca de outras fontes alimentares, como

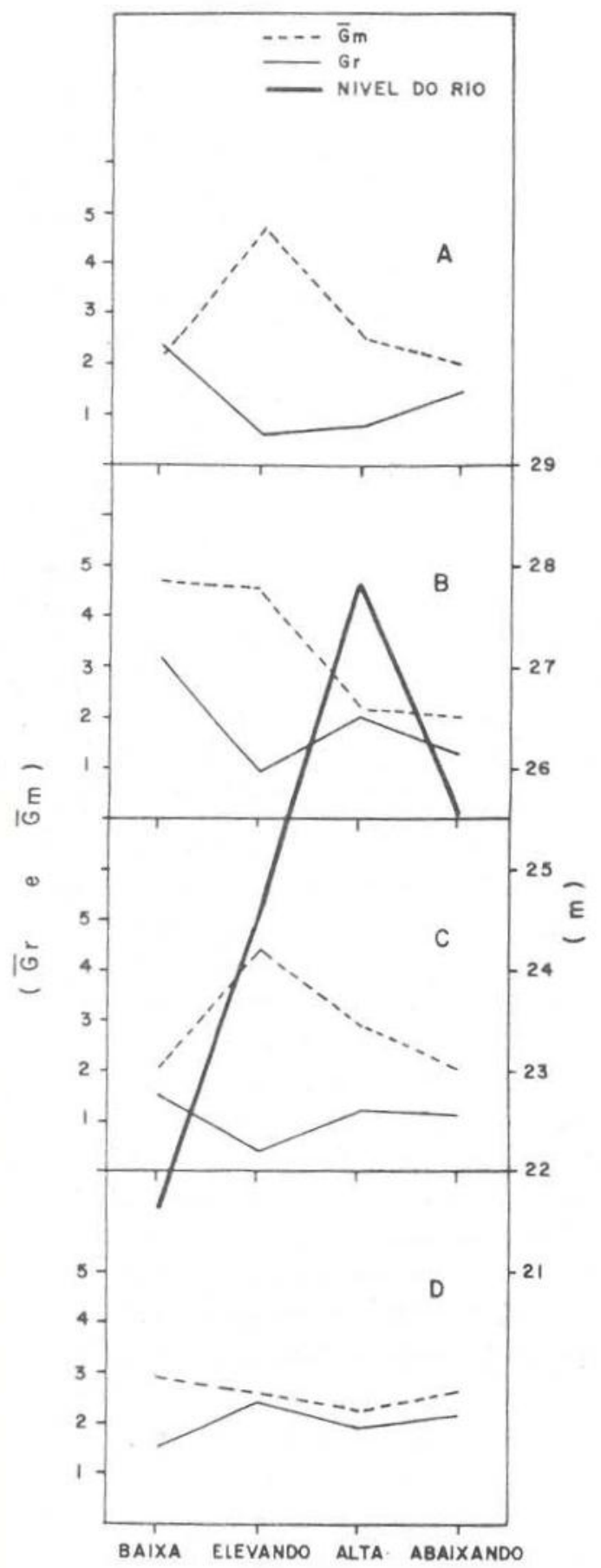

Fig. 19 - Distribuição do grau médio de repleção $(\mathrm{Gr})$ e de maturação $(\mathrm{Gm})$ de Laemolyta varia $(A)$,. Leporinus friderici (B), L. fasciatus (C) e L. trifasciatus (D), nas quatro estaçōes estabelecidas.

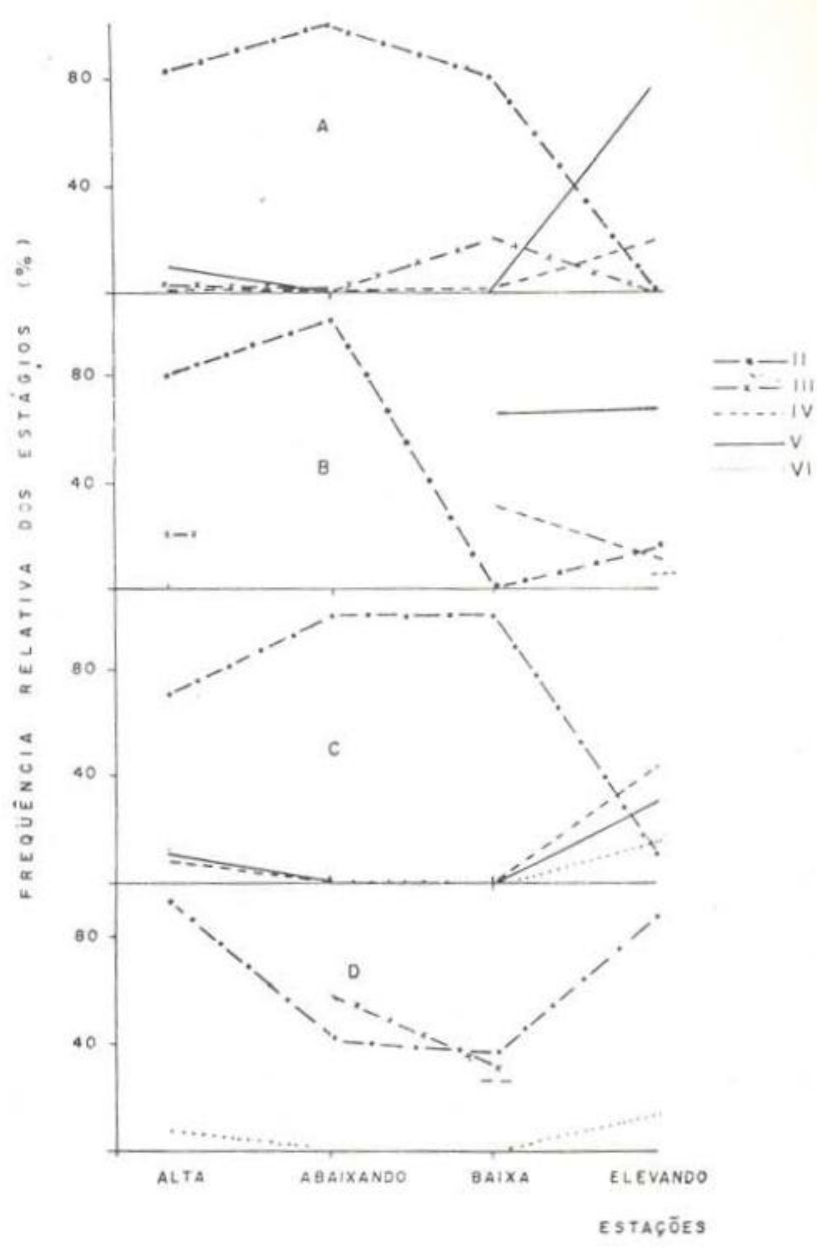

Fig. 20 - Freqüências relativas dos estágios gonadais em L. varia (A), L. friderici (B), L. fasciatus (C) e L. trifasciatus (D), nas diferentes "estações".

frutos e sementes, aumentancio em contrapartida a freqüência de $R$. microlepis, que não sofre destacada alteração quanto ao regime alimentar (Santos, 1981).

As demais espécies de anostomídeos do lago ocorreram durante todo o tempo com freqüência baixa e mais ou menos uniforme.

Os dados de literatura foram suficientes para uma segura identificaçäo das espécies aqui consideradas, entretanto as formas jovens diferiram consideravelmente das adultas, prin. cipalmente quanto ao padrão de colorido, fato não convenientemente tratado ou esclarecido nos trabalhos clássicos da sıstemática ictiológica. Estas informações bem como os dados do estudo da morfologia do trato digestivo comentados a seguir serviram para melhor definir e caracterizar as espécies, ao mesmo tem- 


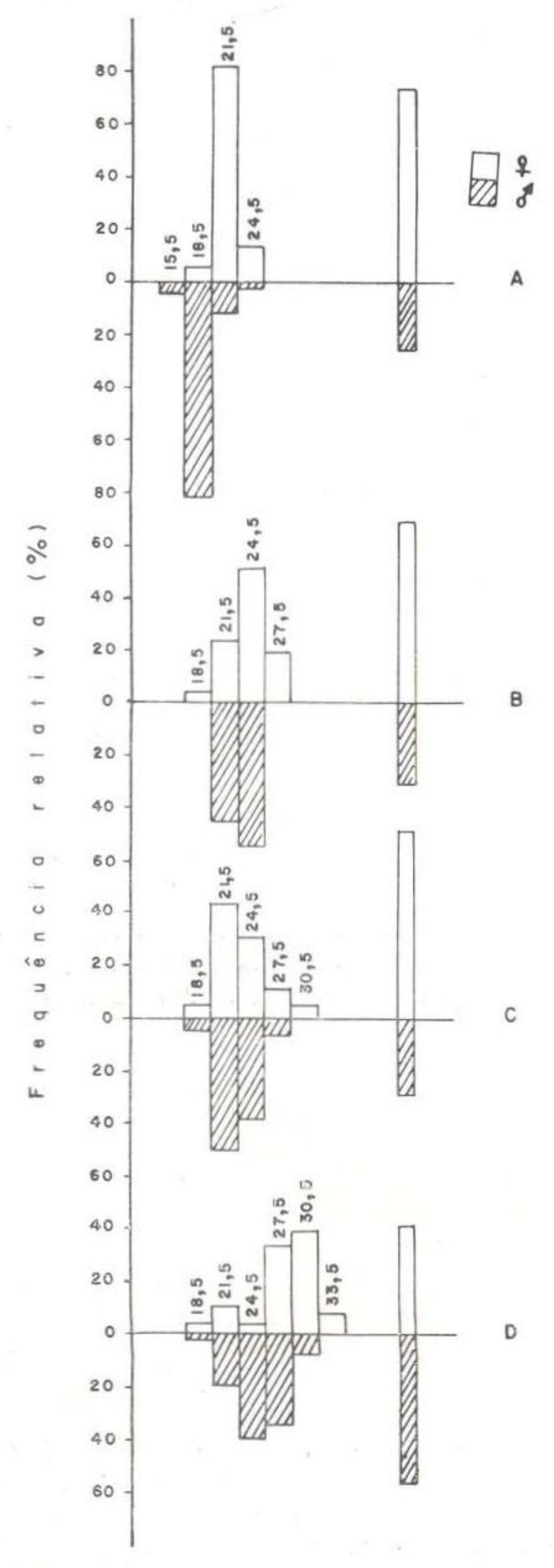

Fig. 21 - Determinação e freqüência relativa dos tamanhos dos Individuos adultos machos e fêmeas (I) e "sex-ratio" (II) de L. varia (A), L. friderici (B), L. fasciatus (C) e L. trifasciatus (D). po que forneceram elementos e subsídios para correlações entre estas estruturas e a bioecologia das espécies.

Os dentes bucais, bem como as mandíbulas das espécies de Leporinus são mais desen. volvidos que as de Laemolyta, o que parece permitir às primeiras, a utilização de alimentos mais duros ou sua retirada de locais mais resistentes, como, por exemplo, a quebra de frutos $\varepsilon$ sementes ou a tomada de ninfas de Efemeroptera do interior de madeiras submersas. Os dentes são usados para tomar, raspar ou quebrar o alimento.

Os rastros branquiais dos anostomídeos parecem não atuar na tomada dos alimentos; Isso parece muito evidente apenas nos peixes planctófagos (geralmente com rastros finos. numerosos e delicados) nos carnivoros (geralmente com rastros duros, em pequeno núme. me e espinhosos) e em alguns bentófagos (rasiros geralmente carnosos ou protuberantes), sendo que nas espécies com outros hábitos alimentares, com as aqui tratadas, eles devem atuar na proteção dos arcos e filamentos branquiais, outra das funções atribuidas a esta: estruturas (Lagler, et ál., 1962; Storer, \& Usinger, 1974). Quanto aos dentes faringeanos, dadas principalmente a posição das placas dentígeras e a disposição das cúspides, parecem atuar diretamente na alimentação, funcionandic como escarificadores ou dilaceradores do material ingerido, mormente sobre o de origem vegetal.

O tipo do estômago e intestino e os coeficientes estomacal e intestinal mostraram-se muito semelhantes entre as diferentes espé. cies de anostomídeos e entre os jovens e adultos, havendo igualmente uma tendência de os estômagos serem maiores e com paredes mais grossas e coeficiente intestinal maior nas es pécies com regime alimentar predominantemente herbivoro.

O padrão de colorido tem servido para a separação de subgrupos entre as espécies de Anostomidae, principalmente em Leporinus Entre estes, geralmente são considerados: a) com barras transversais; b) com listras longi. tudinais; com máculas e d) lisos (Gery, 1977, Britski \& Garavello, 1978). Isso parece ser muito útil apenas para as formas adultas, já que os jovens geralmente apresentam um pa- 
drão de colorido totalmente diverso e praticamente não são considerados nos trabalhos de sistemática (talvez justamente por essa razão). Em L. varia, L. friderici e L. trifasciatus, os jovens apresentaram um pacirão de colorido com barras transversais estreitas e numerosas que desaparecem com o crescimento dos indivíduos. Igualmente, em duas espécies de Rhytiodus anteriormente estudadas (Santos, 1980) observou-se o mesmo fenômeno. Isso evidencia que o padrão barrado é primitivo entre os Anostomidae (Britski \& Garavello, 1978), devendo ao mesmo tempo desempenhar um significado ecológico importante, como possivelmente uma ação mimética protetora para algumas das espécies mais raras (Santos, 1981).

O desconhecimento das variações do padrão de colorido, além de dificultar uma segura identificação de formas jovens baseado nos dados de literatura (geralmente tratando apenas dos caracteres de indivíduos adultos) chegou e pode ainda chegar ao ponto extremo de levar alguns sistematas a descreverem como espécies novas, jovens de espécies já conhecidas. Só coletas intensivas em várias épocas do ano, em diferentes biótopos e com o emprego de diversos aparelhos de pesca é que permitirão elucidar este e semelhantes problemas.

As quatro espécies estudadas apresentaram um regime alimentar do tipo onívoro, havendo um leve predomínio de larvas de insetos aquáticos na alimentação de Leporinus fascia-

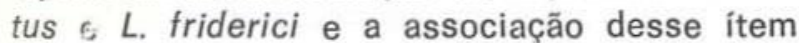
com material vegetal em $L$. varia e Leporinus trifasciatus. O espectro dos itens alimentares mostrou-se muito pequeno nas quatro espécicies, sendo que a dieta não variou pronunciadamente com a idade, ou com as estações do ano. A leve oscilação dos ítens alimentares parece dever-se principalmente à sua disposição ou vulnerabilidade no meio aquático para as espécies que os utilizam.

Os resultados dos trabalhos de Knoppel (1970) com cerca de 40 espécies de peixes de igarapés ao redor de Manaus e os de Goulding (1980) com 50 espécies de peixes dos rios Madeira e Machado mostraranı igualmente que os ítens alimentares não variam nas diferentes épocas do ano, sendo os peixes considerados "oportunistas" quanto ao regime alimentar.

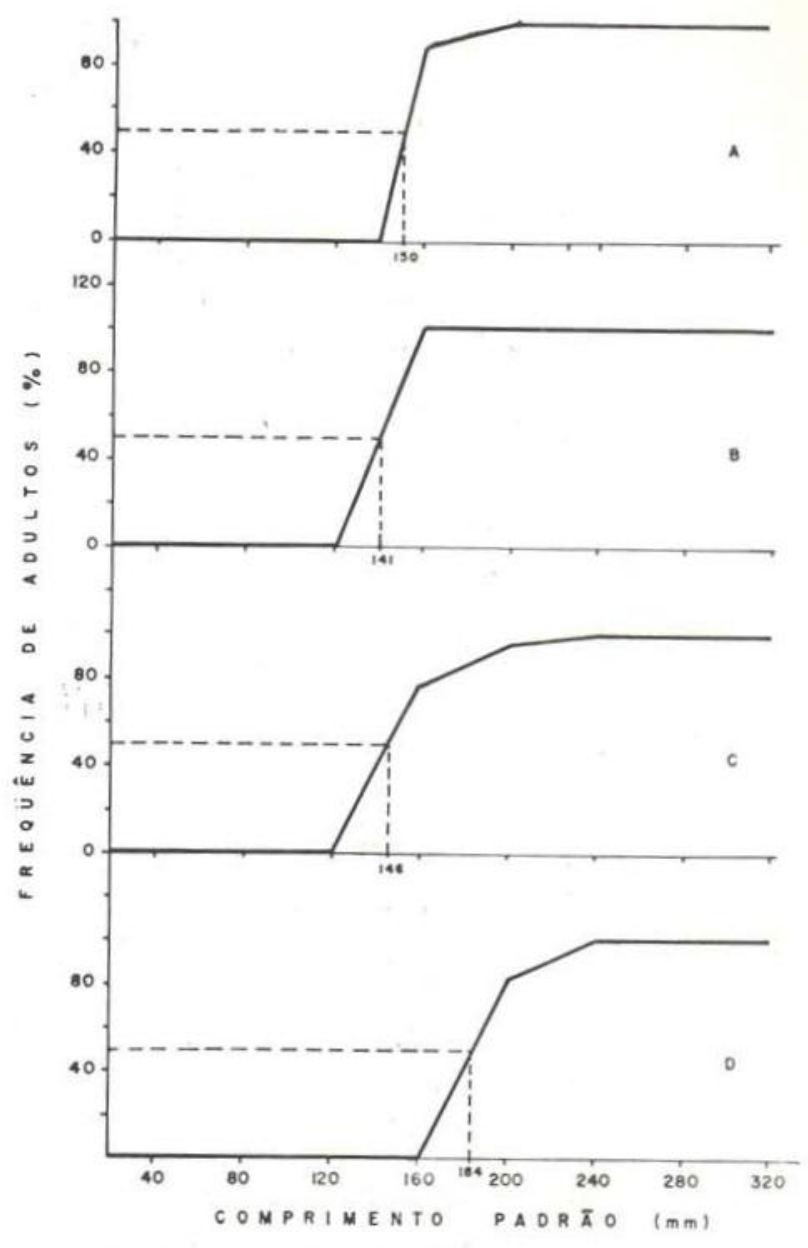

Fig. 22 - Freqüência relativa das diferentes classes de tamanho dos adultos e determinação do tamanho médio da primeira maturaçāo sexual de L. varia (A), L. friderici (B), L. fasciatus (C) e L. trifasciatus (D).

Pelo fato de o ítem predominante (ninfas de Efemeroptera) ser encontrado preferencialmente am madeiras submersas mortas, no se. dimento do funcio e em locais pouco profundo (maicria a menos de $1 \mathrm{~m}$ de profundidade) e de ninfas de Diptera e Moluscos ocorrem geralmente em biótopos semelhantes (Irmler, 1975; Braga, 1979), mostra que estes anastomideos se alimentam no fundo, próximo à margem do lago.

O grau médio de repleção $(\mathrm{Gr})$ geralmente indica a freqüência ou intensidade da atividade alimentar como também, em certos casos, o grau de disponibilidade dos alimentos no meio. Como se observa, estes foram baixos e muito uniformes nas quatro espécies, apresentandose com maiores valores na estação baixa e menores, na "elevando". Isso parece dever-se 
ao fato de que, na estação baixa, os peixes tem uma maior atividade alimentar, preparando-se, através do acúmulo de reservas alimentares no corpo, para a desova na estação "elevando", onde a atividade alimentar é reduzida. Este fato é corroborado pelos resultados de outras espécies de anostomideos estudadas (Santos, 1981) e por muitas observações de campo com outras espécies de caracoideos. Além disso e considerando a estação baixa como a época da redução da maioria das fontes alimentares e do aumento da densidade populacional devida à redução do volume d'água, o fato de os anostomídeos apresentarem maio. res $\mathrm{Gr}$ justamente nesta estação, parece indicar que não há diminuição da oferta de alimentos nu se há, os peixes incrementam suas atividades alimentares.

A oscilação desta atividade parece estar mais relacionada com a própria fisiologia e ecologia das espécies que com a variação do número ou da abundância das fontes alimentares. Em outras palavras, o alimento não parece ser um fator limitante para este grupo de peixes, em nenhuma época, neste local.

Os valores dos coeficientes de sobreposição alimentar, altos para as quatro espécies em todas as estações (maioria acima de 0,5 ou $50 \%$ ) indics que, mesmo explorando em comum muitas fontes alimenteres, o alimento é suficiente para mantê-las nestas condições naturais, sem competição. Os mais baixos valores dos coeficientes de sobreposição alimentar foram os encontrados entre as três espécies esiudadas anteriormente (Santos, 1981) com as espécies de Leporinus do presente estudo. Isso se deu principalmente a que estas últimas tiveram uma alimentação à base de ninfas de insetos aquáticos e aquelas, à base de material vegetal. Ficou evicienciado que os coeficientes de sobreposição alimentar foram maiores entre as espécies congêneres.

Segundo Braga (1979), os efemerópteras (Astenopus cultus) têm uma grande adaptabilidacie a diversos tipos de água e de substratos e são uns dos mais eficientes macroinvertebrados colonizadores e destruidores de madeira submersa na Amazônia. Dada a grande disponibilidade de madeiras acumuladas nos reservatórios artificiais já formados e em projetos na Amazônia, geralmente localizados em rios encachoeirados originários dos planaltos das Guianas e do Brasil Central, portanto química e biologicamente pobres (Sioli, 1968, Junk, 1981), esta ocorrência deve favorecer a proliferação desses macroinvertebrados. Estes, além de desempenharem um importante papel na remineralização e aceleração do ciclo de nutrientes nestes corpos d'água, deverão incrementar o desenvolvimento das populações de peixes que deles se alimentam, como as espécies de Leporinus, ao menos enquanto estas condições se mantiverem suficientes e adequadas para elas.

Os maiores graus médios de maturação, bem como as maiores freqüências dos estâgios gonadais mais avançados ( $\mathrm{V}$ e VI) se deram na estação "elevando". O período de de. sova para estas como para a maioria das espécies de Characoidei na regiăo da Amazônia Central se dá nesta estação, ou seja, por ocasião do maior índice pluviométrico e do inícic da enchente dos rios (Lowe-McConell, 1964; Roberts, 1971, Soares, 1981; Almeida, 1980). $\mathrm{Na}$ verdade, estes simples fatores: chuva e enchente são conseqüência e ao mesmo tempo causa de muitos outros os quais, isolados ou conjuntamente, influenciam ou induzem a desova de determinadas espécies de peixes. Que fatores hidrológicos e ecológicos são esses e como agem não se sabe ainda mas em decorrência de algumas das condições em que eles se processam e de como as espécies se comportam frente a eles, parece que o sentido da correnteza lagindo no direcionamento dos ovos e larvas para os "lares" de alimentação e refúgio que são os lagos de várzea e a maioı incidência de chuvas (possivelmente pela maior oxigenação da superfície da massa líquida onde se encontra em suspensão a maioria dos ovos e larvas) atuam mais fortemente na reprodução desses peixes que outros fatores como luz, temperatura da água, salinidade e ventos importantes principálmente em regiões temperadas (Nikolsky, 1963; Lagler et al.. 1962 e Weber, 1974).

O estágio gonadal que temporariamente predominou entre os anostomideos foi o II ou de repouso (cerca de cinco meses). Seguindose o V (cerca de 4 meses). Os estágios III e 
IV ou de pré desova duraran menos (um a dois meses cada).

Adultos de $L$. varia e $L$. friderici prontos para a desova (estágio V) e em cardume foram encontrados com alta frequeência na entrada do lago ou na área sob infíuência direta das águas barrentas do rio Solimões, havendo ind:cações que estas espécies dependem diretamente delas para desova.

Contrariamente, foram coletados raros adul. tos prontos para a desova e não observados cardumes de L. fasciatus e L. trifasciatus nesta mesma área. Como os alevinos dessas 4 espé. cies ocorrem juntos na mesma época nesta re gião do lago, presume-se que estas 2 espécies desovam no lago, provavelmente nas suas margens ou cabeceiras, não dependendo diretamente para isso das águas do rio Solimões.

Os maiores tamanhos e as maiores freqüências de fêmeas em relação aos machos correspondentes na maioria das espécies de anostomídeos parece indicar uma estratégia para fazer frente as condições adversas que o meio ambiente impõe à espécies como estas: ovuliparas e que não dispensam cuidados à prole. Essa medida asseguraria uma maior produção relativa de óvulos e maior taxa de sobrevivência, possibilitando uma conveniente situação de equilíbrio entre estas e outras populações e espécies no ecossistema.

\section{SUMMARY}

Giving continuity to the study of Amazon anostomids, informations concerning to the caracierization, feeding habits and reproduction of four species (Lae. molyta varia, Leporinus friderici, Leporinus fasciatus and Leporinus trifasciatus) from Janauacá lake are presented. Specimens of various sizes, colected every 15 days during one and half year were analized. Whereas the species are morphologically distinct and casily identified, when growing they suffer profound mocifications in their coloration pattern to the point that the young specimens are very different from the adults. All four species are omnivorous, feeding principally on aquatic insects nymphs and seeds. The species reproduce at the mouth and at the edge of the lake during the flood season (january to april) when the water from the Rĩ Solimões invades the varzea lakes. At this time occurs a great proliferation of the aquatic grasses. under which generally the fry lives. Further conside- rations are given to the morphology of the digestive tract in relation to the feeding habits and some cor. relations between these species and others previously studied are also presented.

\section{REFERENCIAS BIBLIOGRÁFICAS}

ALMEIDA, R.G.

1980 - Aspectos taxonômicos e hábitos alimenta. res de três espécies de Triportheus (Pisces: Characoidei, Characidae) do lago do Castanho, Amazonas. Tese de Mestrado. Manaus, INPA/FUA. $104 p$.

AXELROD, H.R.; EMMER, C.W.; SCULTHORPE, D.;

VORDERWINKLER, W.; PRONEK, N.

1962 - Exotic tropical fishes. J. C. T. F. H. Publications, Inc. $608 \mathrm{p}$.

BORODIN, N.A.

1929 - Notes on some species and subspecies of the genus Leporinus SPIX Mem. Mus. Comp. Zool., Harvard, 50 (3): 269-290.

BRAGA, R.

1979 - Contribuição à Biologia e Ecologia de Asthenopus curtus HAGEN (Insecta - Ephemeroptera) dos arredores de Manaus (Amazônia Central). Tese de Mestrado. Manaus, INPA/FUA. 77p.

BRITSKY, H.A. \& GARAVELLO, J.C.

1978 - Sobre Leporinus octofasciatus STEINDACH. NER da Bacia do Paraná (Pisces, Anostomidae). Pap. Avuls Zool., São Paulo, 31 (16): $237-250$.

1980 - Sobre uma nova espécie de Leporinus da Bacia Amazônica (Pisces, Anostomidae) com consideraçōes sobre L. striatus KNER 1859 e espécies afins. Papéis avulsos de Zoologia, São Paulo, 33 (15): 253-262.

CAMPOS, A.A.

1945 - Contribuição ao estudo das espécies brasileiras do gênero Leporinus. Pap. Avuls. Dep. Zool., São Paulo, 5 (16): 141-158.

CORBET, P.S.

1961 - The food of non-cichlid fishes in the Lako Victoria Basin, with remarks on their evolution and adaptation to lacustrine conditions. Proc. Zool. Soc., Londres, 136: 1-101.

DOURADO, O.F.

1981 - Principais peixes e crustáceos dos açúdes controlados pelo DNOCS. MINTER-DNOCS. 40p.

EIGENMANN, C.H.

1912 - The freshwater fishes of British Guiana, including a study of the ecological grouping of species, and the relation of the fauna of the plateau to that of the lowlands. Memoirs of the Carnegie Museum, 5: XXII $+578 p$. 
FONTENELE, O. \& VASCONCELOS, E.A. de

1977 - Consideraçōes sobre a aclimataçāo dos piaus verdadeiros, Leporinus elongatus CUV. \& VAL. 1864 (Anostomidae) em açudes do Nordeste brasileiro. B. Tec. DNOCS, Fortaleza, 35 (1): 61-92.

FOWLER, H.W.

1948-1951 - Os peixes de água doce do Brasil vol. I. Arq. Zool. Est. São Paulo, 6 (1.: entrega): 1-204 (1948); 6 (2.' entrega): 205-405 (1950) et 6 (3." entrega): 405-625 (1951) (Char.: 31-419).

GARMAN, S.W.

1890 - On the species of the genus Anostomus. Bull. Essex. Inst., Salem, 22 (1-3): 1-23.

GERY, J.

1960 - Contributions a l'étude des poissons Characoides ( $n$. 7) - Validité de Leporinus despaxi Puyo et du sour-genre Hypomasticus Borodin. Bull. Mus. Nat. Hist. Nat. 2." ser., 3 (32): 222-229.

1961 - Contributions á l'étude des Poissons Characoides n. 13. Structure et évolution des Anostomidae. Bull. Aquat. Biol., 2 (19): 93112.

1964 - Poissons Characoides de l'Amazonie peruvienne. Beitr. Neotr. Fauna, 4 (1): 1-44.

$1972 / 73$ - Notes sur quelques Anostomidae (Pisces, Characoidei) du Bassin Amazonien. Vie Milien Sér. C, 23 (1): 143-175.

1977 - Characoids of the World. Neptune city, T.F.H. Publications, Inc. 672p.

GOULDING, M.

1980 - The fishes and the forest. Explorations in Amazonian natural history. Berkeley, Univ. of California Press. 280p.

HYNES, H.B.N.

1950 - The food of freshwater sticklebacks (Gasterosteus oculeatus) and Pygosteus pungitius with a review of methods used in studies of the food of fishes. J. Anim. Ecol., 19: 36-58.

IRMLER, U.

1975 - Ecological studies of the aquatic soil invertebrates in three inundation forests of Central Amazonia. Amazoniana, 5 (3): 397-409.

JUNK, W.J. \& FURCH, K.

1980 - Química da água e macrófitas aquáticas de rios e igarapés na Bacia Amazônica e nas áreas adjacentes. Acta Amazonica, 10 (3): 611-633.

KNOPPEL, H.A.

1970 - Food of Central Amazonian fishes. Contribution to the Nutrient-Ecology of Amazonian Rain-Forest streams. Amazoniana, 2 (3): $257-352$
1972 - Zur Nahrung Tropischer Wusswasserfishe aus Sudamerika: Einige ausgewahlte arten der Anostomidae, Curimatidae, Hemiodidae und Characidae (Pisces, Characoidei), Amazoniana, 3 (2): 231-246.

LAGLER, K.F.; BARDACH, J.E. \& MULLER, R.R.

1962 - Ichthyology: the study of fishes. New York, John Wiley. 545p.

LOWE-McCONNELL, R.H.

1964 - The fishes of the Rupununi Savanna District of British Guiana, South America. I Ecological grouping of fish species and effects of the seasonal cycle on the fish. J. Linn. Soc. (Zool.) 45 (304): 103-144.

MARLIER, G.

1968 - Études sur les lacs de l'Amazonie Centrale. III - Les poissons du Lac Redondo et leur regime alimentaire; les chaines tropi. ques du Lac Redondo; les poissons du rio Preto da Eva. Cadernos da Amazônia, INPA. 57p.

MORISITA, M.

1959 - Measuring of interspecific association and similarity between communities. Mem. Fac. Sci Kyushu Univ. Ser. E (Biology), 3 (1): 65-80.

MYERS, G.S.

1950 - Studies on South American freshwater fishes. !! - The genera of Anostomine, Characids. Stanford Ichthyological Bulletin, 3 (4): 184-198.

NIKOLSKY, G.V.

1963 - The ecology of fishes. London and New York, Academic Press. 352p.

PETRERE Jr., $M$.

1978 - Pesca e esforço de pesca no Estado do Amazonas. II - Locais, aparelhos de captura e estatísticas de desembarque. Acta Amazonica (Supl. 2), 8 (3): 54p.

RINGUELET, R.A.; ARAMBURU, R.H. de \&

ARAMBURU, A.A. de

1967 - Los peces argentinos de aigua dulce. La Plata: Comision de Investigation Cientifica. Prov. Buenos Aires. 602p.

SANTOS, G.M.

1980 - Aspectos de sistemática e morfologia de Schizodon fasciatus AGASSIZ, 1829; Rhytiodus microlepis KNER, 1859 e $\mathbf{R}$. argenteofuscus KNER, 1859 (Osteichthyes, Characoidei, Anostomidae) do lago Janauacá. AM. Acta Amazonica, 10 (3): 635-649.

1981 - Estudos de alimentação e hábitos alimentares de Schizodon fasciatus, AGASSIZ, 1829, Rhytiodus microlepis KNER, 1859 e R. argenteofuscus KNER, 1859 do lago Janauacá, AM. (Osteichthyes, Characoidei, Anostomidae). Acta Amazonica, 11 (2): 267-283. 
SAUL, W.G.

1975 - An ecological study of fish at a site in upper Amazonian Ecuador. Proc. Acad. Nat. Sci. Philad., 127 (12): 93-134.

SIOLI, H.

1968 - Hydrochemistry and geology in the Brazilian Amazon Region. Amazoniana, 1 (3): 267-277.

SOARES, M.G.M.

1978 - Aspectos ecológicos e alimentação dos peixes do igarapé do Porto, Aripuanã, MT. Te se de Mestrado. INPA/FUA. 77p.

STORER, T.I. \& USINGER, R.L.

1971 - Zoologia Geral. Cia. Ed. Nac. São Paulo. $757 p$.

SUDEPE - PDP

1979 - Relatório Técnico Trimestral (Out.-Dez.) Base de Operações em Manaus. (não paginado)
WEBER, W.

1974 - The influence of Hydrogeographical factors on the spawning time of tropical fish. Procceding of the International Seminar on Fisheries Resources and their Managemant in Southeast Asia. German Foundation for International Development. p. 269-281.

WINTERBOTTOM, R.

1980 - Systematics, Osteology and Phylogenetic Relationships of fishes of the Ostariophysan Subfamily Anostomidae (Characoidei, Anostomidae). The Royal Ontario Museum, Life Science Contributions, 123: 1-112.

ZARET, T.M. \& RAND, A.S.

1971 - Competition in tropical stream fishes: support for the competitive exclusion principle. Ecology, 52 (2): 336-342.

(Aceito para publicação em 12/05/82) 